\title{
1 Ambulacrarian insulin-related peptides and their putative \\ 2 receptors suggest how insulin and similar peptides may \\ 3 have evolved from Insulin-like Growth Factor
}

5 Jan A. Veenstra ${ }^{1}$,

6

$7 \quad{ }^{1}$ INCIA UMR 5287 CNRS, Université de Bordeaux, Pessac, France.

8

9 Corresponding Author:

10 Jan A. Veenstra ${ }^{1}$

11 INCIA UMR 5287 CNRS, Université de Bordeaux, allée Geoffroy St Hillaire, CS 50023, 33615

12 Pessac Cedex, France

13 Email address: jan-adrianus.veenstra@u-bordeaux.fr

\section{Abstract}

\section{Background}

22 Some Insulin/IGF-related peptides (irps) stimulate a receptor tyrosine kinase (RTK) that transfers the

23 extracellular hormonal signal into an intracellular response. Other irps, such as relaxin, do not use an 
24 RTK, but a G-protein coupled receptor (GPCR). This is unusual since evolutionarily related hormones

25 typically either use the same or paralogous receptors. In arthropods three different irps, i.e. arthropod

26 IGF, gonadulin and Drosophila insulin-like peptide 7 (dilp7), likely evolved from a gene triplication, as

27 in several species genes encoding these three peptides are located next to one another on the same

28 chromosomal fragment. These arthropod irps have homologs in vertebrates, which suggests that the

29 initial gene triplication was perhaps already present in the last common ancestor of deuterostomes and

30 protostomes. It would be interesting to know whether this is indeed so and how insulin might be related

31 to this trio of irps.

\section{Methodology}

33 Genes encoding irps as well as their putative receptors were identified in genomes and transcriptomes

34 from echinoderms and hemichordates.

\section{Results}

36 A similar triplet of genes coding for irps is also found in some ambulacrarians. Two of these are 37 orthologs of arthropod IGF and dilp 7 and the third is likely a gonadulin ortholog. In echinoderms two 38 novel irps emerged, gonad stimulating substance (GSS) and multinsulin, likely from gene duplications 39 of the IGF and dilp7-like genes respectively. The structures of GSS diverged considerably from IGF, 40 which would suggest they use different receptors than IGF, but no novel irp receptors evolved. If IGF 41 and GSS use different receptors and the evolution of GSS from a gene duplication of IGF is not 42 associated with the appearance of a novel receptor while irps are known to use two different types of 43 receptors, it seems to suggest that the ancestor of GSS and IGF might have acted on both types of 44 receptors while one or both of its descendants act on only one. There are three ambulacrarian GPCRs 45 that have amino acid sequences suggestive of being irp GPCRs, two of these are orthologs of the 46 gonadulin and dilp7 receptors. This suggests that the third might be an IGF receptor, and that by 47 deduction GSS only acts on the RTK. The evolution of GSS from IGF may represent a pattern, where 48 IGF gene duplications lead to novel genes coding for shorter peptides that activate an RTK. It is likely 49 this is how insulin and the insect neuroendocrine irps evolved independently from IGF.

\section{Conclusion}

51 The local gene triplication described from arthropods that yielded three genes encoding irps was 52 already present in the last common ancestor of protostomes and deuterostomes. It seems plausible that 
53 irps, such as those produced by neuroendocrine cells in the brain of insects and echinoderm GSS

54 evolved independently from IGF and thus are not true orthologs, but the result of convergent evolution.

55

56

57 Key words: insulin; relaxin; receptor tyrosine kinase; G-protein coupled receptor; evolution; gonadulin;

58 octinsulin; multinsulin; dilp7 


\section{Introduction}

Many protein hormone and neuropeptide signaling pathways have orthologs in both protostomes and deutertostomes showing that these pathways were already present in their last common bilaterian ancestor. In some cases the orthologs of the peptide ligands show only limited sequence similarity, but their receptors contain protein domains that are sufficiently conserved to establish homology. Virtually all ligands employ either a single receptor or a number of related receptors that evolved by gene duplication. Co-evolution of peptide ligands and receptors insures that related protein hormones or neuropeptides use receptors akin to those of their orthologs (Mirabeau \& Joly, 2013; Hsueh \& Feng, 2020).

Insulin/IGF-related peptides (irps) are an exception to this rule. Whereas insulin and IGF act through a receptor tyrosine kinase (RTK), relaxin uses a leucine-rich repeat G-protein coupled receptor (LGR). This raises the interesting question as how this apparent jump from one type of receptor to another may have come about. In cockroaches, termites and stick insects three different irp genes, gonadulin, arthropod insulin-like growth factor (aIGF) and arthropod relaxin, are located next to one another in the genome and thus likely originated from a local gene triplication (Veenstra, 2020b). To avoid confusion with the vertebrate relaxins and related peptides, the arthropod relaxins will be referred to as Drosophila ilp7 (dilp7) in this manuscript. One of theirps, aIGF, is known to use an insulin RTK, while gonadulin acts through insect LGR3 (Vallejo et al., 2015; Garelli et al., 2015; Colombani et al., 2015). Bioinformatic evidence suggested that dilp7 must be the ligand for insect LGR4 and this has now been confirmed experimentally in Drosophila (Veenstra, Rombauts \& Grbić, 2012; Imambocus et al., 2020), but dilp7 may also activate an RTK (Linneweber et al., 2014). This suggests that the archtype arthropod IGF-related peptide acted through both an RTK and an LGR and that after a likely gene triplication, some of the ligands may have lost one of the two original receptors. Although it is possible that the gene triplication of the ancestral insulin gene occurred in an early arthropod or protostomian, it may well have occurred in a bilaterian ancestor, as homologs of both aIGF and dilp7 are also present in deuterostomes.

Brain neuroendocrine insect irps are more closely related to IGF than either dilp7 or gonadulin and a gene duplication that gave rise to separate genes encoding these peptides is therefore likely to have occurred after the triplication that gave rise to the ancestor genes of gonadulin and dilp7. Yet in insect genomes irp genes are not located near the IGF gene. Thus the particular organization of these genes suggests that whereas the gonadulin and dilp7 genes likely originated by two successive local gene 
90 duplications, the IGF gene duplication that gave rise to an initial arthropod neuroendocrine brain irp

91 must have materialized in a different fashion. If the earlier mentioned gene triplication was already

92 present in the last common ancestor of the deuterostomes then a similar argument can also be made for

93 the evolution of insulin. Given the importance of insulin as a human hormone and the inherent interest

94 of its evolutionary origin, I explored the evolution of bilaterian insulin-related peptides in more detail

95 and here report on the genes coding for such peptides and their receptors in the Ambulacraria that

96 suggest how insulin may have evolved from IGF.

\section{Materials and Methods}

99 Nomenclature

100 Hormones have often been discovered independently by different groups using different bioassays.

101 The vertebrate insulin-like growth factors are a good example of that. Predicted protostomian peptides

102 and their receptors have sometimes been given names that refer to similar deuterostomian proteins. In

103 some cases this is very confusing, e.g. vertebrate LGR-3, -4 and -5 are not the orthologs of arthropod

104 receptors that have been given the same names. A similar problem occurs with arthropod relaxin that is

105 not an ortholog of vertebrate relaxin. This peptide will therefore be called dilp7 (Drosophila insulin-

106 like peptide 7). I will refer to arthropod LGR3 as the gonadulin receptor, arthropod LGR4 as the dilp7

107 receptor and arthropod LGR5 as GRL101, a GPCR initially identified from the pond snail Lymnaea

108 stagnalis (Tensen et al., 1994) that is an ortholog of arthropod LGR5 (Veenstra, 2020b).

109 Another nomenclature problem concerns the terms, insulin-like and insulin-related that are not well

110 defined. Insulin and IGF are related and must share a common evolutionary origin with other peptide

111 ligands like vertebrate relaxin, INSL3, arthropod dilp7 and gonadulin and a large number of other

112 bilaterian peptides. All these peptides are often collectively called insulin-like or insulin-related without

113 any specification as to in which aspects these hormones are similar to insulin. The typical core

114 sequence of six cysteine residues and its use of an RTK are two characters that are shared by vertebrate

115 IGF and insulin. However, several related peptides have eight cysteine residues and others like

116 vertebrate relaxin use an LGR and not an RTK. Insulin and IGF are also different in that IGF is a single

117 chain molecules, while the insulin precursor is processed into a two chain molecule. The term insulin-

118 like seems more appropriate for a subset of the insulin/IGF-related peptides that look similar to insulin

119 and act through an RTK, yet are different from IGF. Calling IGF-related peptides like vertebrate

120 relaxin, INSL3 or arthropod gonadulin for which there is no evidence that they act through an RTK, 
121 insulin-like is confusing. Unfortunately for many bilaterian peptides we can only speculate as to which

122 type of receptor they use. The difference between one or two chain ligands, i.e. IGF versus insulin, is

123 also useless as there is good evidence that some insect IGF-related peptides are processed into two-

124 chain molecules when expressed in neuroendocrine cells and produced as single chain ligands when

125 produced by the fat body, yet in both cases stimulate an RTK. It is for these reasons that all these

126 peptides will be referred to as insulin/IGF-related peptides, abbreviated irps.

\section{Sequence analysis}

129 Sequences for insulin related peptides and their likely receptors were identified from a number of

130 Ambulacraria species. This was done using using the Artemis program (Rutherford et al., 2000) and the

131 BLAST+ program (ftp://ftp.ncbi.nlm.nih.gov/blast/executables/blast+/) on publicly available genome

132 sequences from the feather star Anneissia japonica, the sea urchins Lytechinus variegatus (Davidson et

133 al., 2000) and Strongylocentrus purpuratus (Sea Urchin Genome Sequencing Consortium, 2006), the

134 sea cucumbers Apostichopus japonicus (Jo et al., 2017; Zhang et al., 2017) and Holothuria glaberrima,

135 the sea stars Acanthaster planci (Hall et al., 2017), Pisaster ochraceus (Ruiz-Ramos et al., 2020) and

136 Patiria miniata, the brittle star Ophiothrix spiculata and the hemichordates Saccoglossus kowalevskii

137 and Ptychodera flava (Simakov et al., 2015). The genomes were downloaded from

138 https://www.ncbi.nlm.nih.gov/genome. For many of these species there are also significant amounts of

139 RNAseq data and these were analyzed using the sratoolkit

140 (https://race.ncbi.nlm.nih.gov/Traces/sra/sra.cgi?view=software ) in combination with Trinity

141 (Grabherr et al., 2011) using methods described in detail elsewhere (Veenstra, 2020b). Some protein

142 sequences were found in the NCBI database, but several of them contain errors or are incomplete.

143 Where possible these were corrected and/or completed using the methods described above. As there is

144 only a single crinoid genome assembly available, transcriptome data from the three crinoid species

145 Antedon mediterranea, Florometra serratissima and Oligometra serripinna were also included. For the 146 same reason transcriptome data from the brittle star Amphiura filliformis, Ophioderma brevispina and

147 the hemichordate Schizocardium californicum were likewise analyzed. Obviously, transcriptome data

148 can only demonstrate the presence of gene but not its absence and their usefulness depends largely on

149 the variety of tissues sampled and the expression levels of the genes of interest. Nevertheless, such data

150 often provide additional sequences that even if they are incomplete increase the robustness of sequence

151 comparisons. Genomic and transcriptomic RNAseq short read archives (SRAs) were downloaded from 
152 NCBI (https://www.ncbi.nlm.nih.gov/sra/); a list of the SRAs analyzed is provided in the

153 supplementary data.

154 As queries for the insulin-like peptides a number of such peptides from a variety of species was 155 used. Insulin RTKs are easily identified in genome and transcriptome assemblies, as their kinase 156 domains are very well conserved. The LGRs that could function as insulin receptors are more variable.

157 Vertebrate RXFP1 and RXFP2 are LGRs are known receptors for relaxin and Ins3 and Drosophila

158 LGR3 and LGR4 for gonadulin, and dilp7 respectively. Other LGRs function as receptors for the 159 various glycoprotein hormones, GPA2/GPB5, bursicon, TSH, FSH and LH. These GPCRs cluster on

160 phylogenetic trees with another protostomian LGR, GRL101. This GPCR was initially identified from

161 the pond snail Lymnaea stagnalis and was the first GPCR discovered to have in addition to six leucine-

162 rich repeats also twelve repeats of a sequence that was known to exist in the low density lipoprotein

163 receptor and are now called LDLa repeats (Tensen et al., 1994). I have suggested previously (Veenstra, 164 2020b) that this receptor might be an IGF receptor.

165 Both the RTK and LGR receptors have large ectodomains. Those of the insulin RTKs are very 166 similar from one receptor to another, while those of the LGRs differ between different types. The latter 167 all contain numerous Leucine-rich repeats (LRRs) and some also have LDL-receptor class A (LDLa) 168 repeats. Both LRRs and LDLa's are present in many other proteins. Initial searches for orthologous 169 receptors were therefore done using the transmembrane regions of various insect and vertebrate LGRs 170 and the protein kinase domain of RTK. Once partial sequences of putative receptors were identified, the 171 coding sequences of these domains were then used to complete the cDNA sequences as best as 172 possible, using either Trinity on RNAseq SRAs or Artemis on genome sequences.

Sequence similarity and phylogenetic trees

175 Both phylogenetic and sequence similarity trees use Clustal omega (Sievers et al., 2011) to produce 176 alignments. Fasttree (Price, Dehal \& Arkin, 2010), using the ./FastTreeDbl command with the -spr 4, 177 mlacc 2 and -slownni options, was used to construct trees and estimate probabilities.

178 In order to identify putative receptors for the various irps, LGRs that show homology to various 179 arthropod and vertebrate LGRs were identified and a phylogenetic tree based exclusively on the 180 transmembrane regions of these receptors was constructed.

181

\section{Precursor processing}


Precursors of insulin-like peptides contain signal peptides that are removed on entry into endoplasmatic reticulum. Signal P 5.0 (Almagro Armenteros et al., 2019) was used online (http://www.cbs.dtu.dk/services/SignalP/) to predict where this cleavage would most likely occur. in all cell types and can thus potentially cleave any secreted protein with appropriate cleavage site. Its consensus cleavage site is $\mathrm{K} / \mathrm{R}-\mathrm{X}-\mathrm{K} / \mathrm{R}-\mathrm{R}$, the two human IGF precursors are processed at KSAR and KSER respectively (Humbel, 1990). Precursors that are produced in cells with a regulated pathway, such as neuroendocrine and enteroendocrine cells, are also exposed to other convertases like PC1/3 and PC2. Their consensus cleavages site is KR. However, effective proteolytic processing by convertases is strongly influenced by amino acid residues surrounding these consensus cleavage sites. For example bulky residues immediately following the arginine residue, a proline residue before the consensus site or disulfide bridges nearby can cause sufficient steric hindrance to inhibit cleavage. Using rules proposed to predict cleavage by PC1/3 and PC2 in both vertebrates and insects (Devi, 1991; Rholam et al., 1995; Veenstra, 2000) I have tried to indicate in Figs. 3-6 where the various precursors might be cleaved. It must be noted though that there is no certainty that these site will be cleaved nor can it be excluded that proteolytic processing occurs at sites that have not been indicated as such.

\section{Expression}

With a few notable exceptions (e.g. Lin et al., 2017), little is known about the expression of the various insulin-like peptides in either echinoderms or hemichordates and except for the GSS our knowledge of their functions is also very limited. Expression data may reveal some preliminary clues as to where and when they are expressed and thus provide a hint as to their function. For this reason the number of reads corresponding to the various insulin-related peptides and their putative receptors was determined in a number of SRAs that might provide evidence as to the time and tissue specific expression of these proteins. The analysis was performed as described previously (Veenstra, 2020b)

\section{Results}

\section{Peptides related to insulin and IGF}


Some protein sequences were found in the NCBI database, but several of them contain errors or are

214 incomplete. Where possible these were corrected and/or completed using the methods described above.

215 As there is only a single crinoid genome assembly available, transcriptome data from the three crinoid

216 species Antedon mediterranea, Florometra serratissima and Oligometra serripinna were also included.

217 For the same reason transcriptome data from the brittle star Amphiura filliformis, Ophioderma

218 brevispina and the hemichordate Schizocardium californicum were likewise analyzed. Obviously,

219 transcriptome data can only demonstrate the presence of gene but not its absence and their usefulness

220 depends largely on the variety of tissues sampled and the expression levels of the genes of interest.

221 Nevertheless, such data often provide additional sequences that even if they are incomplete increase the 222 robustness of sequence comparisons.

223 Insulin-like peptide precursors are typically characterized as having A, B and C domains that 224 correspond to the A- and B-chains of insulin and the connecting peptide respectively. In IGF D and E 225 domains are also recognized, in which the D domain refers to the extension of the A chain and the $\mathrm{E}$ 226 domain to part of the precursor after the D domain that is cleaved from IGF in the Golgi apparatus. For 227 dilp7 orthologs it is appropriate to add an F (front) domain for the sequence in N-terminal of the B228 chain that in some peptides is not only larger, but also well conserved (Fig. 1).

229 Previous work on insulin-related peptides in in echinoderms have identified two different types of 230 insulin-like peptides, gonad-stimulating substances (GSS) and insulin-like growth factors (Mita et al., 231 2009; Perillo \& Arnone, 2014; Semmens et al., 2016; Smith et al., 2019). The insulin-like growth

232 factors, but not GSS, are also present in hemichordates. While only a single IGF gene was found in the 233 crinoids and hemichordates, other ambulacrarians have two such genes (Figs. 2, S1, S2; Spreadsheet

$234 \mathrm{~S} 1)$. These proteins have large C-terminal extension that are rich in charged amino acid residues,

235 especially arginine and lysine, but also aspartic and glutamic acid residues. A comparison of the protein 236 sequences and cDNAs from human IGFs identifies the exact separation between the D and E domains

237 in these proteins (Humbel, 1990). However, although the corresponding sequences of the hemichordate

238 and echinoderm IGFs contain numerous arginine and lysine residues (Figs. 2, S1, S2), there are no

239 obvious convertase cleavage sites as many potential arginine residues are succeeded by residues known

240 to inhibit such enzymes in vertebrates. It is thus not impossible that the D domains of these proteins are

241 much larger than in the vertebrate IGFs and if so likely contain numerous positively charged amino

242 acid residues. There are few transcriptome SRAs for specific tissues, the data that is available suggest

243 that the IGFs are expressed by many tissues, with the ovary showing significant expression. Patiria 
pectinifera is the only species with follicle cell specific SRAs and IGF-1 is strongly expressed by these cells and is probably transferred to the oocyte (Spreadsheet S2).

The GSS are known to induce oocyte maturation and ovulation in a two step process, where GSS stimulates the follicle cells to produce 1-methyladenine which subsequently induces resumption of meiosis in the oocyte and about 30 minutes later this is followed by ovulation (Chiba, 2020). Interestingly, GSS was not found in either the genome nor the extensive transcriptome data from the feather star Anneissia japonica and was similarly not encountered in the transcriptomes of three other crinoids (Suppl data). Transcriptomes may miss expression of some genes and large genome assemblies are never perfect. The short sequence reads in the genomic SRAs from Anneissia were therefore also analyzed for the presence of GSS, but again no evidence for such a gene was found. This peptide is thus likely absent from Anneissia and perhaps all Crinoidea. In the Holothuroidea and the Asterozoa, but not the Echinoidea, this gene is duplicated with the two paralogous peptides showing significant sequence variability (Figs. 3, S3, S4; Spreadsheet S1). As for all these peptides and their putative receptors expression data is very limited, but in Apostichopus the two GSSs are differentially expressed, with GSS-1 being expressed at specific stages during embryonic development as well as by muscle and GSS-2 strongly expressed by both the ovary and the testes. Interestingly, it is the ortholog of GSS-1 that in Holothuria scabra has been tested for biological activity and induces ovulation (Chieu et al., 2019). This makes one wonder what the effects of GSS-2 on ovulation might be in this species. However, Apostichopus was the only species where a significant GSS expression was found in the gonads (Spreadsheet S2).

Two other insulin-like peptides are commonly present in both hemichordates and echinoderms, including the Crinoidea. The first is an ortholog dilp7 which has a very characteristic F domain while its A chain is also remarkably well conserved (Figs. 4, S5, S6; Spreadsheet S1). The precursors of this peptide contain typical neuroendocrine KR convertase sites and seems to have its highest expression in the nervous system, although it is also found in other tissues. During embryogenesis its expression occurs relatively late (Spreadsheet S2). The second peptide present in all ambulacrarians has been called octinsulin as it has eight cysteine residues and is thus predicted to have four rather than three disulfide bridges. In echinoderms octinsulin is a single copy gene, but hemichordates have several such genes (Fig. 5, S7, S8; Spreadsheet S1). Octinsulin expression levels are the highest in nervous tissue, and significant expression is also found in the gut and stomach of Strongylocentrotus and Patiria 
pectinifera respectively. Although virtually absent from normal gut in Apostichopus, it has significant

275 expression during gut regenerating in this species (Spreadsheet S2).

276 The Asterozoa have genes coding for a fifth type of insulin, that is usually present in multiple

277 copies and that are referred to as multinsulins. The predicted peptides share structural similarity with

278 the dilp7 orthologs and their genes have typically four coding exons rather than the two or three of the

279 other irp genes. The sprawl of these peptides is perhaps best illustrated by a phylogenetic tree that

280 suggest independent multiplication of these genes in several species (Fig. S10). Within a single species

281 the various multinsulins thus often seem more closely related to one another than to their putative

282 orthologs of other Asterozoa. Some of the multinsulins, like the octinsulins, have acquired two

283 additional cysteine residues and are thus predicted to have four disulfide bridges, but the location of

284 these additional cysteine residues differs from that in octinsulins (Figs. 6, 7, S9, S10; Spreadsheet S1).

285 Like dilp7 the multinsulins have typical neuroendocrine KR convertase cleavage sites and can thus be

286 expected to be expressed in neuroendocrine and/or enteroendocrine cells but expression data on $P$.

287 pectinifera suggest a relatively ubiquitous expression in several tissues.

288 The genome assemblies of A. planci and Pisaster ochraceus shows these genes to be clustered in

289 the genome and some RNAseq sequences suggests that at least on occasion coding exons from different

290 genes may be combined (Fig. S10). This and the large numbers of SNPs typically present in animals

291 caught in nature and used for RNAseq preparation make it impossible to reliably determine their exact 292 numbers.

293 Genome assemblies allow identification of the introns in these genes. All insulin genes have a 294 characteristic phase 1 intron somewhere in the conceptual $\mathrm{C}$ domain of these molecules. This is the 295 only intron in the coding sequences of the octinsulin and GSS genes. The IGF genes have a phase 0 296 intron near the end of the coding sequence and at least some of them have another phase 1 intron just 297 after the transcription start site. The genes coding for the dilp7 orthologs and multinsulins share an 298 additional phase 2 intron and the multinsulin genes have yet another phase 1 intron. All these introns 299 appear perfectly conserved (Fig. 7).

\section{Synteny of genes producing insulin-like peptides}

302 In the Strongylocentrotus genome all five genes are located on the same chromosome, with the two 303 IGF genes and those encoding octinsulin and dilp7 orthologs next to one another and GSS at a distance 304 of 6,000,000 bp (base pairs). At least the Anneissia octinsulin and IGF genes are likely located next to 
305

306

one another on the same chromosome also, as in the current genome assembly two of the three coding exons of IGF and one of the two octinsulin coding exons are located within about 10,000 bp. The three missing exons of these two genes are all located on minicontigs of less than 2,000 bp, as is one of the coding exons for the dilp7 ortholog. The contigs of the Lytechinus variegatus genome assembly are smaller and this may explain why in this species the genes are located on three different scaffolds, with the two ILGF-like peptides and the octinsulin together on a single contig. However in the recently published genome of the closely related L. pictus (Warner et al., 2021) the dilp7 ortholog is also closely associated with the other three genes. The GSS gene is on the same chromosome but at a distance of 28,000,000 bp. In the Apostichus japonicus genome assembly the genes encoding the octinsulin and the two IGF genes are located on the same contig, and the other genes each on a different one. In the draft Holothuria glaberrima genome assembly only the two IGF genes are located on the same contig, however in a single Oxford nanopore read (SRR9125585.2851.1) from H. scabra the octinsulin, dilp7 and two IGF genes are located next to one another as well (Fig. 8).

Whereas the various Echinozoa genome assemblies suggest a certain degree of synteny with regard to the various irp genes, the Asterozoa genome shows that such syntenty is disintegrating. This is most clearly demonstrated in the genome assemblies from Pisaster ochraceus and Acanthaster planci, where the scaffolds are much larger than from Patiria miniata. In these species synteny is largely lost (Fig. 8). Interestingly the various multinsulin genes are present in small clusters on different chromosomes in those species.

\section{Sequence similarity tree peptides related to insulin}

Peptides having the characteristic insulin signature are notoriously variable in their primary amino acid sequences. Although the various residues allows one to align those sequences, such alignments will not always yield reliable phylogenetic trees as the basic tenet of such analyses is often not met. As an alternative I have proposed to use "sequence similarity trees". Such trees are constructed using the same methods but do not pretend to illustrate phylogenetic relations, rather similarities between the different proteins.

The structures of the multinsulins are most similar to the dilp7 orthologs (Fig. 6) and so it is not surprising that the sequence similarity tree (Fig. 9) groups the multinsulins with the dilp7 orthologs. The hypothesis that this structural similarity between these two types of peptides may reflect a close evolutinary relationship is reinforced by the presence of an intron that is present in the genes encoding 
these peptides but lacking in the genes encoding octinsulin, IGF and GSS (Fig. 7). The tree also

illustrates significant sequence similarity between GSS and the IGF.

Orthologs of receptors for irps: Receptor tyrosine kinase

A single insulin RTK gene was found in all species analyzed here. An alternatively spliced form is present in Acanthaster and is likely commonly present in echinoderms (Spreadsheet S1). Hundreds of ambulacrarian protein sequences were identified at NCBI using a BLAST search with the S. kovalevskii protein kinase domain as a query. After aligning them with Clustal omega the protein kinase domains were used to make a phylogenetic tree. Results revealed no other known or predicted proteins with a similar protein kinase domain (data not shown). The insulin RTK is ubiquitously expressed

Orthologs of receptors for irps peptides: LGRs

LGR sequences were obtained using the combination of genomic sequences and, where available, transcriptome shotgun sequences and RNAseq SRAs. The latter were used to produce contigs using

351 Trinity (Spreadsheet S1). Short read assemblers are good in combining sequences into larger continuous ones, but they do produce artifacts, which are more easily obtained when very similar sequences are present in multiple copies, such as the multinsulins, or the numerous LDLa and LRR repeats. These repeats are usually individually coded by single exons that are sometimes skipped and when such skipped individual reads enter in the RNAseq SRA, incorrect constructs are obtained. Furthermore, these repeats are present in numerous proteins, and from time to time this leads to assembled sequences that are from mRNA species from different genes. It is therefore to be expected that not all assembled transcripts, neither those in the databank nor those produced here, will be correct.

359 Some errors were corrected by challenging divergent sequences that were discovered on comparing 360 putative orthologs with one another. Other differences could be confirmed as true differences, but it is 361 not impossible that some errors remain, particularly for those sequences that are incomplete. LGRs that 362 might function as receptors for the various irps were identified by their homology with such receptors 363 from vertebrates and arthropods. The transmembrane regions of the GPCRs don't have the assembly 364 problems of the LDLa and LRR repeats and are the most characteristic domain of the GPCRs. This makes it easier to construct a phylogenetic trees for these receptors based on their transmembrane regions than that it is to produce complete LGR transcripts. 
Results show a surprisingly similar distribution of LGRs in the species studied. The tree resolves

368

369

370

371

372

373

374

375

376

377

378

379

380

381

382

383

384

385

386

387

388

389

390

391

392

393

394

395

396

two major branches, one for the glycoprotein hormone receptors, which itself is divided in two subbranches, one for orthologs of the GPA2/GPB5 receptor - containing the receptors for human TSH, FSH and LH - and a second one for the bursicon receptor orthologs. All species studied are represented by one member on each of these two subbranches, except for Ophiothrix, where the draft genome reveals two orthologs each for the bursicon and GPA2/GPB5 receptors (Fig. 10). These are likely receptors for the bursicon and GPA2/GPB5 orthologs identified from various echinoderm species (Semmens et al., 2016). It is interesting to see that whereas vertebrates have different receptors for TSH, FSH and LH, most echinoderms have only one GPA2/GPB5-receptor ortholog (Fig. S11), even though A. rubens has two GPA2 and three GPB5 orthologs (Semmens et al., 2016). The LGRs for the glycoproteins were included in the search for putative receptors for the ambulacrarian irp LGRs in order to be sure that no such receptors would be missed.

The lower branches of the LGR phylogenetic tree are the ones of interest as they contain receptors with irp ligands. It consists of three subbranches, that are characterized by Drosophila LGR3 and LGR4 - the receptors for gonadulin and dilp7 respectively - and Periplaneta LGR5, an ortholog of Lymnaea GRL101. Here in all ambulacrarian species studied only one ortholog was found for each of them, despite extensive attempts to find additional LGRs in the various genomes and transcriptomes.

The GRL101 transmembrane regions puts it very close to vertebrate glycoprotein hormone and relaxin LGRs. LRRs are present in many different proteins, but when the LRR part of the Anneissia GRL101 (amino acid residues 576-717) is used as query in a protein BLAST against human proteins, the glycoprotein hormone and relaxin receptors are identified as most similar to this ectodomain of GRL101, suggesting that similarity of the GRL101 receptors with vertebrate LGRs is not limited to the transmembrane region of this GPCR.

Sequence alignments of these GPCRs show strong sequence similarity (Figs. S12-S14), however the dil7 receptor ortholog varies more between species. A schematic representation of the the ectodomains of the LGRs on this second branch is drawn in Fig. 11. The orthologs of the dilp7 and gonadulin receptors each have a single LDLa repeat, except for the Patiria and Acanthaster orthologs of the dilp7 receptor which both have two LDLa repeats (Fig. S13). This additional LDLa is likely due to a relatively recent duplication of the LDLa since the two LDLa repeats have very similar amino acid sequences (Spreadsheet S1). All three receptors are expressed in the nervous system and the gonadulin 
receptor is well expressed in the gonads, both testis and ovary, and strongly so in the follicle cells of $P$.

398 pectinifera (Spreadsheet 2).

400 Discussion

401 The genomic and transcriptomic data from both the hemichordates and the echinoderms show that 402 these two groups share three irps, octinsulin, IGF and a dilp7 orthologs, that are present in both 403 echinoderms and hemichordates. IGF and dilp7 are orthologs of the arthropod peptides that together 404 with gonadulin originated from a gene triplication. The structure of gonadulin is poorly maintained, 405 even within insects (Veenstra, 2020b). The variable structure of gonadulin and its loss in many 406 arthropod lineages suggests that the evolutionary pressure on gonadulin is weak. This may explain why 407 the amino acid sequence of gonadulin looks significantly different from octinsulin. Nevertheless, there 408 are two lines of evidence that suggest that these peptides must be orthologs as well. For one, synteny of 409 the chromosome fragment containing these genes is conserved between the sea urchin

410 Strongylocentrotus purpuratus, the hemichordate Saccoglossus kowalewski and the cockroach Blattella 411 germanica, suggesting that these peptides are likely orthologs. More importantly, all ambulacrarians 412 have an ortholog of the gonadulin receptor and the only plausible ligand for such a receptor encoded by 413 their genomes is octinsulin. Thus the gene triplication previously reported from arthropods must have 414 occurred in a common bilaterian ancestor of the deuterostomes and protostomes.

415 Crinoids have the simplest irp signaling system, one gene each for IGF, octinsulin and the dilp7 416 ortholog. Their putative receptors - insulin RTK, GRL101, and the orthologs of the dilp7 and gonadulin 417 receptors - similarly are also each coded by a single gene. The hemichordates have a very similar 418 repertoire, except that the octinsulin gene is systematically amplified and in some species the dilp7 419 ortholog as well. It thus appears likely that the first deuterostome had a single copy of each of these 420 genes.

421 Within the echinoderms the irp genes evolved considerably, as shown both by an increase in their 422 numbers and the loss of synteny. Whereas the feather stars appear to have only a single IGF gene, all 423 other echinoderms have two such genes and two novel irps, GSS and multinsulin, appeared. The GSS 424 sequences are most similar to those of IGF, suggesting that they evolved from a gene duplication event 425 from the IGF gene. Although some GSS genes are located on the same chromosome as the other irps, 426 they are not close to the IGF genes, indicating that the IGF-GSS split was not a local duplication but 427 may have been the result of an incorrectly repaired chromosome break. 
In the Asterozoa a fifth type of irp gene emerged, those that code for the multinsulins which share significant sequence similarity with the dilp7 orthologs. The initial multinsulin gene must thus have its origin in a gene duplication of the dilp7 ortholog gene, with which they furthermore share a

431 characteristic intron. Later the multinsulin gene seems to have undergone several additional gene duplications in this respect the multinsulins resemble the insect neuroendocrine irps.

The co-evolution of ligands and receptors allows one to assign the putative receptors for gonadulin, the dilp7 ortholog and IGF as the orthologs of the receptors of their arthropod orthologs. This allows the identification of the ambulacrarian LGRs that are the orthologs of the gonadulin and dilp7 receptors as likely receptors for octinsulin and the dilp7 respectively, as well as the insulin RTK as a receptor for 437 IGF.

438 The appearance of the multinsulins is not accompanied by the evolution of a novel insulin-receptor. Some animals have multiple insulin RTKs, e.g. some arthropods have up to four such genes (Veenstra, 2020a,b), however, in spite of extensive searches for a second insulin RTK in ambulacrarian genomes, none was found. Searches for an additional LGR that might function as a receptor for the GSS and/or

442 multinsulin were unsuccessful and this raises the question which receptors are activated by these 443 peptides.

444 I have previously argued that the close chromosomal association of the IGF, gonadulin and dilp7 445 ortholog genes in basal insects suggest that they derived from a gene triplication (Veenstra, 2020b).

446 There are three possible scenarios that can explain how IGF and gonadulin came to respectively 447 activate an RTK and an LGR. It is possible that the original irp activated either an RTK and that an 448 LGR was later acquired as a second receptor by gonadulin, alternatively the original irp activated an 449 LGR and IGF acquired an RTK as a second receptor. Given the importance of insulin RTKs for growth 450 in very basal metazoans, it is improbable that the original irp activated an LGR and that an RTK was 451 acquired much later during evolution (see e.g. Mortzfeld et al., 2019). This indicates that an irp 452 acquired an LGR as a second receptor and the question is whether this happened before or after the 453 gene triplication that yielded IGF, gonadulin and dilp7. In both Saccoglossus and arthropods the IGF 454 gene is in the middle of the three. This suggests that this represents the gene organisation after the gene 455 triplication and that the dilp7 and gonadulin orthologs each evolved independently from the arch irp 456 rather than that dilp7 evolved from gonadulin or vice versa. Had dilp7 originated from a gene 457 duplication of gonadulin or the other way round, they also might have been more similar to one another 458 than they are. The acquisition of a second receptor must be an extremely rare event. Since both 
gonadulin and dilp7 use an LGR this would mean that such an extremely rare event of the acquisition

460 of a second receptor would have occurred not only twice, but even with a very similar receptor.

461 Furthermore, some metazoans have an LGR that is closely related to the dilp7 and gonadulin LGRs

462 suggesting that it could be an IGF receptor (see below). It is for these reasons that the author favors the

463 hypothesis that the arch irp already acted on both an LRG and an RTK, but, clearly, this remains a

464 hypothesis.

465 The binding of insulin and relaxin to their respective receptors has gotten resolved in much detail 466 in the last couple of years. The effective binding and stimulation of insulin RTK by the small irp from 467 the snail Conus to the RTK shows that a small irp can be an effective ligand for this receptor (Menting 468 et al., 2015). On the other hand the complex interaction of relaxin to its LGR makes it more difficult to 469 imagine a smaller peptide as an effective ligand (Hoare et al., 2019). Furthermore, considering the well 470 conserved F-domain of the dilp7 receptor orthologs it is likely that it is necessary for interaction with 471 its LGR receptor. The loss of this structure in multinsulin suggests that it is unlikely to be a dilp7 472 receptor agonist. On the other hand, the poor sequence conservation in the various Drosophila irps that 473 activate a single RTK is reminiscent of the large structural variability of the multinsulins. This seems to suggest that the multinsulins are RTK ligands rather than that they activate the LGR.

The emergence of the GSS is neither accompanied with the evolution of a novel receptor for these irps. This can also be explained by assuming that IGF acts on both the RTK and an LGR and that the GSS have lost their affinity for the LGR. This raises the question whether an IGF LGR might exist.

480 for gonadulin and dilp7. The ectodomain of GRL101 consists of two parts, a series of LRRs and a 481 second series of LDLa's. In the related GPCRs the LRRs are expected to bind with the insulin core of 482 gonadulin and dilp7 orthologs, just like the human relaxin receptors (Hoare et al., 2019). When the 483 LRR part of the Anneissia GRL101, the most basal echinoderm, was used as query for similar human 484 proteins in a BLAST search, the glycoprotein hormone and relaxin receptors were identified as the most similar proteins. This shows that the resemblance of GRL101 to the other LGRs is not limited to

486 the transmembrane regions and reinforces the hypothesis that the ligand of GRL101 has an insulin-like 487 structure. GRL101 has a large number of LDLa's, the ligands of which are typically positively charged 488 surfaces, which in the case of proteins consist of Lys and Arg residues (Daly et al., 1995; Prévost \& 489 Raussens, 2004; Fisher, Beglova \& Blacklow, 2006; Yasui, Nogi \& Takagi, 2010; Dagil et al., 2013). 
490 Thus the ligand of GRL101 may consist of two parts, an insulin-like structure and a piece with several

491 positive charges that interact with the LDLa's. The C-terminal tails of the IGFs, whether from

492 arthropods, echinoderms or hemichordates, are all rich in charged amino acid residues. The C-terminal

493 tail of IGF with its numerous positively charged amino acid residue might interact with the LDLa's of

494 GRL101. I therefore posit that in those species that have a GRL101 it functions as the second receptor

495 for IGF. The absence of such a tail in GSS would make it likely that it acts on the RTK rather than an

496 IGF GPCR.

497 The suggestion that GSS activates the RTK goes against the hypothesis that these peptides act

498 through GPCRs. Indeed it has recently been proposed that it is the ortholog of the dilp7 receptor that

499 would be activated by the gonad stimulator in P. miniata (Mita et al., 2020). Given the clear orthology

500 of both the dilp7 echinoderm orthologs with the Drosophila peptide and the similar orthology between

501 the dilp7 receptor and the echinoderm receptor, the conclusion that the two constitute a functional

502 ligand receptor combination seems inescapable. It was impossible to find a GSS in either the genome

503 assembly or the individual reads of all the genomic SRAs of Anneissia japonica, yet it does have a

504 dilp7 receptor ortholog, thus if the dilp7 receptor were to function as a GSS receptor, it most likely

505 would not be an exclusive receptor. A priori this does not exclude the possibility that GSS could

506 function as a ligand for the same receptor. As mentioned above, since the dilp7 orthologs have well

507 conserved $\mathrm{F}$ domains, one has to assume that it is important for binding to its receptor. Since this

508 domain is absent from RTK ligands, it is difficult to understand how GSS that similarly lacks this

509 domain would be able to bind the dilp7 receptor. It would thus seem unlikely that peptides as different

510 as GSS and dilp7 would be effective ligands of the same LGR. Furthermore, the GSS genes have been

511 duplicated and their structures have diverged considerably. Those duplicate gonad stimulators are

512 present in many species and have not been selected against. Hence they must be phyisologically

513 relevant and able to interact with a receptor. Sharing a common evolutionary origin the two gonad

514 stimulators should be expected to act either on the same or paralogous receptors, but the number of

515 putative echinoderm receptors for irps is limited, so it must be the same one. The same arguments that

516 were used to argue that the multinsulins are likely RTK agonists but not LGR ligands, are therefore

517 equally valid here and suggest that GSS is an RTK ligand.

518 Furhermore, the experimental evidence that GSS stimulates the ortholog of the dilp7 receptor is not 519 convincing. The reported response to the dilp7 receptor when expressed in Sf9 cells is very weak and 520 does not represent a typical response seen in this type of assay. Although the authors have shown high 
521 affinity binding of GSS to the follicle cells, such high affinity binding should also have been present in

522 the Sf9 cells expressing the putative GSS receptor, but this was not reported. The follicle cell SRAs

523 from which the putative GSS receptor was identified contains large amounts of RNAseq reads for the

524 gonadulin receptor, a receptor that is more closely related to the vertebrate relaxin receptors than the

525 dilp7 receptor, but surprisingly the authors do not mention this receptor, which they must have found

526 (Mita et al., 2020).

527 I suggest that initially there was an IGF-like hormone that activated both a GPCR and an RTK,

528 after two gene duplications some of the descendant ligands either lost their C-terminal tails or one

529 acquired a larger one and this allowed all three ligands to activate, at least initially, the RTK while each

530 acquired its own LGR. Later, some of the ligands may have lost their affinity for one receptor. Since

531 the primary amino acid sequence of gonadulin is very different from that of the other irps, it likely lost

532 its capacity to activate the RTK (Fig. 12). Holometabolous insect species have lost GRL101 and hence

533 in those species IGF can only act on the RTK. Under this hypothesis the arginine-rich C-terminal tail

534 would be useless in such insect species and in higher flies, such as Drosophila, it was indeed lost

535 (Veenstra, 2020b). In vertebrates, there is no GRL101 and so IGF can only activate the two RTKs,

536 while the relaxin related peptides are not known to interact with RTK. The presence of a similar

537 arginine-rich E domain of the vertebrate IGF precursors might thus be an evolutionary relict.

538 This scheme raises the question as to how the functions of these two receptors activated by IGF

539 might differ. IGF and the drosophila irps stimulate growth, the echinoderm GSS stimulates oocyte

540 maturation and ovulation (Mita et al., 2009), relaxin and INSL3 affet various developmental and

541 reproductive processes (Ivell et al., 2020; Esteban-Lopez \& Agoulnik, 2020), gonadulin is expressed by

542 the gonads as well as the imaginal in flies (Garelli et al., 2012; Liao \& Nässel, 2020; Veenstra, 2020b;

543 Veenstra et al., 2021) and dilp7 is expressed in a sex specific manner (Miguel-Aliaga, Thor \& Gould,

544 2008; Yang et al., 2008; Castellanos, Tang \& Allan, 2013). These hormones stimulate growth,

545 development and reproduction, processes that are intimately linked; without growth and development

546 reproduction is impossible and growth without reproduction is useless in sexually reproducing species.

547 On the other hand, resources used for growth and development can not be used for reproduction or vice 548 versa.

549 Growth is rarely a linear process independent of development; animals are not only getting bigger,

550 but they also mature into adults. Metamorphosis is markedly different between hemi- and holo-

551 metabolous insect species. Every time a cockroach nymph molts, it becomes a little more adult, 
however during the first molts of a caterpillar the insects mainly become bigger, it is only when it molts into a pupa that it significantly changes its morphology. Cockroaches have GRL101, caterpillars don't. This suggests that the RTK might be more directed toward linear growth, or allowing growth by increasing uptake of resources, such as glucose and amino acids, while the LGRs might be more important for insuring that the animal develops into an adult and becomes sexually competent. Both holometabolous insects and vertebrates have lost GRL101 and use steroid hormones to induce sexual maturation. Interestingly, in vertebrates the production of steroid hormones is controlled by glycoprotein hormones, the second group of ligands for LGRs.

It is plausible that IGF in an early bilaterian was produced by the tissue that stored energy and perhaps even protein as insects do in the form of storage proteins (Haunerland, 1996). Production and release of IGF might have happened when the animal had sufficient resources to allow for growth and/or reproduction. In arthropods growth has become a discontinuous process in which a new cuticle needs to be made before molting can take place. In those species IGF produced by the fat body may well be the essential growth hormone. However, if the animal is suddenly starved, IGF would no longer be released. If formation of a new cuticle is too advanced to be interrupted, this become problematic. It may have obliged the brain to take at least partial control of growth away from the fat body by releasing one or more of the neuroendocrine irps to force growth and molting to proceed. It is possible that this achieved by simultaneously reducing growth of organs that are needed for (sexual) maturation but not essential for immediate survival, like the gonads. This could be how the neuroendocrine insect irps initially evolved. In echinoderms IGF probably stimulates growth of the follicles and oocytes, but the final growth spurt, the one that permits resumption of meiosis in the oocytes and subsequent ovulation, is delayed until optimal conditions to do so prevail. When the time and place are right the nervous system releases GSS likely in large amounts to finish the maturation process and induce ovulation. In vertebrates, growth and the release of IGF has also been brought under control of the brain but more forcefully by bringing IGF secretion by the liver under control of growth hormone. Whereas in an early ancestor high plasma concentrations of insulin might have led to secretion of IGF, this is no longer the case. Here insulin may have evolved to insure that plasma concentrations of glucose are kept sufficiently low by insuring its absorption by tissues in order to avoid it loss by excretion. In the three cases these peptides have very different functions, ovulation in echinoderms, sparing glucose in vertebrates and rescuing interrupted growth in insects. It is plausible then that these hormones each evolved from a non-local IGF gene duplication and that they are thus not proper 
583

584

585

586

587

588

589

590

591

592

593

594

595

596

597

598

599

600

601

602

603

604

605

606

607

608

609

610

611

612

613

614

615

616

617

orthologs but evolved by convergent evolution. This hypothesis would explain, why there is no insulin gene located near the IGF, octinsulin/gonadulin and dilp7 triplet in cockroaches, echinoderms and hemichordates, even though insulin - and other peptides such as the insect neuroendocrine insulin-like peptides and GSS - almost certainly evolved from IGF much later.

\section{Conclusions}

The gene triplication previously reported from arthropods must have occurred in a common bilaterian ancestor of the deuterostomes and protostomes. The hypothesis that IGF in an ancestral bilaterian used both a GPCR and an RTK may explain the combination of echinoderm irps and putative insulin receptors. This hypothesis implies that insulin is not a hormone that evolved before the split between protostomes and deuterostomes, but that insulin-like peptides evolved independently in different metazoan clades as miniature copies of IGF capable to activate the RTK but unable to stimulate the LGR.

\section{Acknowledgements}

This manuscript benefited from the critical contributions of an editor and two reviewers for which I am most grateful. Work like this is only possible because others made their transcriptome and genomic sequences publicly available. I express my sincere gratitude to all of them.

\section{References}

Almagro Armenteros JJ, Tsirigos KD, Sønderby CK, Petersen TN, Winther O, Søren Brunak S, von Heijne G, and Nielsen H. 2019. SignalP 5.0 improves signal peptide predictions using deep neural networks. Nat Biotechnol. 37:420-423, doi:10.1038/s41587-019-0036-z.

Castellanos MC, Tang JC, Allan DW. 2013. Female-biased dimorphism underlies a female-specific role for post-embryonic ilp7 neurons in Drosophila fertility. Development. 140:3915-3926. doi:

10.1242/dev.094714.

Chiba K, 2020. Oocyte maturation in starfish. Cells 9, 476. doi:10.3390/cells9020476.

Chieu HD, Turner L, Smith MK, Wang T, Nocillado J, Palma P, Suwansa-Ard S, Elizur A, Cummins SF. 2019. Aquaculture breeding enhancement: Maturation and spawning in sea cucumbers using a recombinant relaxin-like sonad-stimulating peptide. Front Genet. 10:77. doi:

10.3389/fgene.2019.00077. 
Colombani J, Andersen DS, Boulan L, Boone E, Romero N, Virolle V, Texada M, Léopold P. 2015.

Drosophila Lgr3 couples organ growth with maturation and ensures developmental stability. Curr Biol. 25:2723-2729. doi: 10.1016/j.cub.2015.09.020.

Dagil R, O'shea C, Nykjær A, Bonvin AM, Kragelund BB. 2013. Gentamicin binds to the megalin receptor as a competitive inhibitor using the common ligand binding motif of complement type repeats insight from the NMR structure of the 10th complement type repeat domain alone and in complex with gentamicin. J. Biol. Chem. 288, 4424-4435. doi: 10.1074/jbc.M112.434159.

Daly NL, Scanlon MJ, Djordjevic JT, Kroon PA, Smith R. 1995. Three-dimensional structure of a cysteine-rich repeat from the low-density lipoprotein receptor. Proc Natl Acad Sci U S A. 92:6334-8. doi: $10.1073 /$ pnas.92.14.6334.

Davidson PL, Guo H, Wang L, Berrio A, Zhang H, Chang Y, Soborowski AL, McClay DR, Fan G, Wray GA. 2020. Chromosomal-level genome assembly of the sea urchin Lytechinus variegatus substantially improves functional genomic analyses. Genome Biol Evol. 12:1080-1086. doi: 10.1093/gbe/evaa101.

Devi L. 1991. Consensus sequence for processing of peptide precursors at monobasic sites. FEBS Lett 280:189-194. doi: 10.1016/0014-5793(91)80290-j.

Esteban-Lopez M, Agoulnik AI, 2020. Diverse functions of insulin-like 3 peptide. J Endocrinol. 247:R1-R12. doi: 10.1530/JOE-20-0168.

Garelli A, Gontijo AM, Miguela V, Caparros E, Dominguez M. 2012. Imaginal discs secrete insulinlike peptide 8 to mediate plasticity of growth and maturation. Science. 336:579-582. doi: $10.1126 /$ science. 1216735 .

Garelli A, Heredia F, Casimiro AP, Macedo A, Nunes C, Garcez M, Dias ARM, Volonte YA, Uhlmann T, Caparros E, Koyama T, Gontijo AM. 2015. Dilp8 requires the neuronal relaxin receptor Lgr3 to couple growth to developmental timing. Nat Commun. 6:8732. doi: 10.1038/ncomms9732.

Fisher C, Beglova N, Blacklow SC. 2006. Structure of an LDLR-RAP complex reveals a general mode for ligand recognition by lipoprotein receptors. Molecular Cell 22, 277-283. doi: 10.1074/jbc.M112.434159.

Grabherr MG, Haas BJ, Yassour M, Levin JZ, Thompson DA, Amit I, Adiconis X, Fan L, Raychowdhury R, Zeng Q, Chen Z, Mauceli E, Hacohen N, Gnirke A, Rhind N, di Palma F, Birren BW, Nusbaum C, Lindblad-Toh K, Friedman N, Regev A. 2011. Full-length transcriptome assembly from RNA-Seq data without a reference genome. Nat Biotechnol. 15;29:644-652. doi: $10.1038 /$ nbt.1883.

Hall MR, Kocot KM, Baughman KW, Fernandez-Valverde SL, Gauthier MEA, Hatleberg WL, Krishnan A, McDougall C, Motti CA, Shoguchi E, Wang T, Xiang X, Zhao M, Bose U, Shinzato C, Hisata K, Fujie M, Kanda M, Cummins SF, Satoh N, Degnan SM, Degnan BM. 2017. The crown-of- 
664

665

666

667

668

669

670

671

672

673

674

675

676

677

678

679

680

681

682

683

684

685

686

687

688

689

690

691

692

693

694

695

696

697

698

699

700

701

702

703

704

705

706

707

708

709

710 thorns starfish genome as a guide for biocontrol of this coral reef pest. Nature. 544:231-234. doi: 10.1038 /nature22033.

Haunerland NH, 1996. Insect storage proteins: gene families and receptors. Insect Biochem Mol Biol. 26:755-65. doi: 10.1016/s0965-1748(96)00035-5.

Hoare BL, Bruell S, Sethi A, Gooley PR, Lew MJ, Hossain MA, Inoue A, Scott DJ, Bathgate

RAD.2019. Multi-component mechanism of H2 Relaxin binding to RXFP1 through NanoBRET kinetic analysis. iScience. 2019 Jan 25;11:93-113. doi: 10.1016/j.isci.2018.12.004.

Hsueh AJW, Feng Y, 2020. Discovery of polypeptide ligand-receptor pairs based on their co-evolution. FASEB J. 34:8824-8832. doi: 10.1096/fj.202000779R.

Humbel RE, 1990. Insulin-like growth factors I and II. Eur J Biochem. 190:445-62. doi:

10.1111/j.1432-1033.1990.tb15595.x.

Imambocus BN, Wittich A, Tenedini F, Zhou F, Hu C, Sauter K, Varela EM. Herédia F, Casimiro AP, Macedo A, Schlegel P, Yang CH, Miguel-Aliaga I, Pankratz MJ, Gontijo AM, Cardona A, Soba P, 2020. Discrete escape responses are generated by neuropeptide-mediated circuit logic. bioRxiv preprint doi:10.1101/2020.09.22.307033.

Ivell R, Alhujaili W, Kohsaka T, Anand-Ivell R. 2020. Physiology and evolution of the INSL3/RXFP2 hormone/receptor system in higher vertebrates. Gen Comp Endocrinol. 299:113583. doi:

10.1016/j.ygcen.2020.113583.

Jo J, Oh J, Lee HG, Hong HH, Lee SG, Cheon S, Kern EMA, Jin S, Cho SJ, Park JK, Park C. 2017. Draft genome of the sea cucumber Apostichopus japonicus and genetic polymorphism among color variants. Gigascience. 6:1-6. doi: 10.1093/gigascience/giw006.

Liao S, Nässel DR. 2020. Drosophila insulin-like peptide 8 (DILP8) in ovarian follicle cells regulates ovulation and metabolism. bioRxiv. doi: 10.1101/2020.05.02.073585.

Lin M, Mita M, Egertová M, Zampronio CG, Jones AM, Elphick MR., 2017. Cellular localization of relaxin-like gonad-stimulating peptide expression in Asterias rubens: New insights into neurohormonal control of spawning in starfish. J Comp Neurol. 525:1599-1617. doi: 10.1002/cne.24141.

Linneweber GA, Jacobson J, Busch KE, Hudry B, Christov CP, Dormann D, Yuan M, Otani T, Knust E, de Bono M, Miguel-Aliaga I., 2014. Neuronal control of metabolism through nutrient-dependent modulation of tracheal branching. Cell 16;156:69-83. doi: 10.1016/j.cell.2013.12.008.

Menting JG, Gajewiak J, MacRaild CA, Chou DH, Disotuar MM, Smith NA, Miller C, Erchegyi J, Rivier JE, Olivera BM, Forbes BE, Smith BJ, Norton RS, Safavi-Hemami H, Lawrence MC., 2015. A minimized human insulin-receptor-binding motif revealed in a Conus geographus venom insulin. Nat Struct Mol Biol. 23:916-920. doi: 10.1038/nsmb.3292.

Miguel-Aliaga I, Thor S, Gould AP. 2008. Postmitotic specification of Drosophila insulinergic neurons from pioneer neurons. PLoS Biol 6: e58. doi:10.1371/journal.pbio.0060058.

Jan A Veenstra

Ambulacrarian insulin-related peptides

page 23 
Mirabeau O, Joly JS. 2013. Molecular evolution of peptidergic signaling systems in bilaterians. Proc Natl Acad Sci U S A. 110: E2028-37. doi: 10.1073/pnas.1219956110.

Mita M, Yoshikuni M, Ohno K, Shibata Y, Paul-Prasanth B, Pitchayawasin S, Isobe M, Nagahama Y. 2009. A relaxin-like peptide purified from radial nerves induces oocyte maturation and ovulation in the starfish, Asterina pectinifera. Proc Natl Acad Sci U S A. 106:9507-12. doi: 10.1073/pnas.0900243106.

Mita M, Matsubara S, Osugi T, Shiraishi A, Wada A, Satake H. 2020. A novel G protein-coupled receptor for starfish gonadotropic hormone, relaxin-like gonad-stimulating peptide. PLoS One. 15:e0242877. doi: 10.1371/journal.pone.0242877.

Mortzfeld BM, Taubenheim J, Klimovich AV, Fraune S, Rosenstiel P, Bosch TCG. 2019. Temperature and insulin signaling regulate body size in Hydra by the Wnt and TGF-beta pathways. Nat Commun. 10:3257. doi: 10.1038/s41467-019-11136-6.

Perillo M, Arnone MI. 2014. Characterization of insulin-like peptides (ILPs) in the sea urchin Strongylocentrotus purpuratus: insights on the evolution of the insulin family. Gen Comp Endocrinol. 205:68-79. doi: 10.1016/j.ygcen.2014.06.014.

Prévost M, Raussens V. 2004. Apolipoprotein E-low density lipoprotein receptor binding: study of protein-protein interaction in rationally selected docked complexes. Proteins 55:874-84. doi: 10.1002/prot.20080.

Price MN, Dehal PS, Arkin AP. 2010. FastTree 2--approximately maximum-likelihood trees for large alignments. PLoS One. 5:e9490. doi: 10.1371/journal.pone.0009490.

Rholam M, Brakch N, Germain D, Thomas DY, Fahy C, Boussetta H, Boileau G, Cohen P. 1995. Role of amino acid sequences flanking dibasic cleavage sites in precursor proteolytic processing. The importance of the first residue C-terminal of the cleavage site. Eur J Biochem. 227:707-714. doi: 10.1111/j.1432-1033.1995.tb20192.x.

Ruiz-Ramos DV, Schiebelhut LM, Hoff KJ, Wares JP, Dawson MN. 2020. An initial comparative genomic autopsy of wasting disease in sea stars. Mol Ecol. 29:1087-1102. doi: 10.1111/mec.15386.

Rutherford K, Parkhill J, Crook J, Horsnell T, Rice P, Rajandream MA, Barrell B. 2000. Artemis: sequence visualization and annotation. Bioinformatics 16:944-5. doi:

10.1093/bioinformatics/16.10.944.

Sea Urchin Genome Sequencing Consortium. 2006. The genome of the sea urchin Strongylocentrotus purpuratus. Science 314: 941-952.

Semmens DC, Mirabeau O, Moghul I, Pancholi MR, Wurm Y, Elphick MR. 2016. Transcriptomic identification of starfish neuropeptide precursors yields new insights into neuropeptide evolution. Open Biol. 6:150224. doi: 10.1098/rsob.150224. 
Sievers F, Wilm A, Dineen D, Gibson TJ, Karplus K, Li W, Lopez R, McWilliam H, Remmert M, Söding J, Thompson JD, Higgins DG. 2011. Fast, scalable generation of high-quality protein multiple sequence alignments using Clustal Omega. Mol Syst Biol. 7:539. doi: 10.1038/msb.2011.75.

\section{Simakov O, Kawashima T, Marlétaz F, Jenkins J, Koyanagi R, Mitros T, Hisata K, Bredeson J,} Shoguchi E, Gyoja F, Yue JX, Chen YC, Freeman RM Jr, Sasaki A, Hikosaka-Katayama T, Sato A, Fujie M, Baughman KW, Levine J, Gonzalez P, Cameron C, Fritzenwanker JH, Pani AM, Goto H, Kanda M, Arakaki N, Yamasaki S, Qu J, Cree A, Ding Y, Dinh HH, Dugan S, Holder M, Jhangiani SN, Kovar CL, Lee SL, Lewis LR, Morton D, Nazareth LV, Okwuonu G, Santibanez J, Chen R, Richards S, Muzny DM, Gillis A, Peshkin L, Wu M, Humphreys T, Su YH, Putnam NH, Schmutz J, Fujiyama A, Yu JK, Tagawa K, Worley KC, Gibbs RA, Kirschner MW, Lowe CJ, Satoh N, Rokhsar DS, Gerhart J. 2015. Hemichordate genomes and deuterostome origins. Nature. 527:459-465. doi: 10.1038 /nature 16150 .

Smith MK, Chieu HD, Aizen J, Mos B, Motti CA, Elizur A, Cummins SF. 2019. A Crown-of-Thorns Seastar recombinant relaxin-like gonad-stimulating peptide triggers oocyte maturation and ovulation. Gen Comp Endocrinol. 281:41-48. doi: 10.1016/j.ygcen.2019.05.009.

Tensen CP, Van Kesteren ER, Planta RJ, Cox KJ, Burke JF, van Heerikhuizen H, Vreugdenhil E. 1994. A $G$ protein-coupled receptor with low density lipoprotein-binding motifs suggests a role for lipoproteins in G-linked signal transduction. Proc Natl Acad Sci U S A. 91:4816-4820. doi: 10.1073/pnas.91.11.4816.

Vallejo DM, Juarez-Carreño S, Bolivar J, Morante J, Dominguez M. 2015. A brain circuit that synchronizes growth and maturation revealed through dilp8 binding to Lgr3. Science. 50:aac6767. doi: 10.1126/science.aac6767.

Veenstra JA. 2000. Mono- and dibasic proteolytic cleavage sites in insect neuroendocrine peptide precursors. Arch Insect Biochem Physiol. 43:49-63. doi: 10.1002/(SICI)15206327(200002)43:2<49::AID-ARCH1>3.0.CO;2-M.

Veenstra JA. 2020a. Gonadulins, the fourth type of insulin-related peptides in decapods. Gen Comp Endocrinol. 296:113528. doi: 10.1016/j.ygcen.2020.113528.

Veenstra JA. 2020b. Arthropod IGF, relaxin and gonadulin, putative orthologs of Drosophila insulinlike peptides 6,7 and 8, likely originated from an ancient gene triplication. 10: e9534. doi: 10.7717 peerj. 9534 .

Veenstra JA, Rombauts S, Grbić M. 2012. In silico cloning of genes encoding neuropeptides, neurohormones and their putative G-protein coupled receptors in a spider mite. Insect Biochem Mol Biol. 42:277-295. doi: 10.1016/j.ibmb.2011.12.009.

Veenstra JA, Leyria J, Orchard I, Lange A. 2021. Identification of gonadulin and insulin-like growth factor from migratory locusts and their importance in reproduction in Locusta migratoria. Front Endocrinol., in press. 
803 Warner JF, Lord JW, Schreiter SA, Nesbit KT, Hamdoun A, Lyons DC. 2021. Chromosomal-level 804 genome assembly of the painted sea urchin Lytechinus pictus, a genetically enabled model system for 805 cell biology and embryonic development. Genome Biol Evol:evab061. doi: 10.1093/gbe/evab061.

807 Yang CH, Belawat P, Hafen E, Jan LY, Jan YN. 2008. Drosophila egg-laying site selection as a system 808 to study simple decision-making processes. Science 319: 1679-1683. doi: 10.1126/science.1151842.

\section{9}

810 Yasui N, Nogi T., Takagi J. 2010. Structural basis for specific recognition of reelin by its receptors.

811 Structure 18, 320-331. doi: 10.1016/j.str.2010.01.010.

812

813 Zhang X, Sun L, Yuan J, Sun Y, Gao Y, Zhang L, Li S, Dai H, Hamel JF, Liu C, Yu Y, Liu S, Lin W, 814 Guo K, Jin S, Xu P, Storey KB, Huan P, Zhang T, Zhou Y, Zhang J, Lin C, Li X, Xing L, Huo D, Sun 815 M, Wang L, Mercier A, Li F, Yang H, Xiang J. 2017. The sea cucumber genome provides insights into 816 morphological evolution and visceral regeneration. PLoS Biol. 15:e2003790. doi:

817 10.1371/journal.pbio.2003790. 


\section{Figure 1}

Domains of insulin/IGF-related peptides.

Human insulin and IGF and Drosophila dilp7 are aligned and the different domains that are recognized in the precursors of these peptides are indicated. In insulin the domain borders are the convertase cleavage sites that are hihglighted in red. The A- and B-domains of insulin correspond to the A- and B-chains of insulina and the C-domain to the connecting peptide. Although IGF consists of a single protein chain due to its strong sequences similarity to insulin the A- and B-domains correspond to homologous regions of those domains in insulin, while the C-domain is the sequence between the A- and B-domains. In insulin there is only a single amino acid residues after the last cysteine residue, but in IGF there is a longer sequence, that has been called the D-domain. The IGF precursor is cleaved by furin in the Golgi apparatus and the sequence that is removed has been called the E-domain. Dilp7 is only known from nucleotide sequences, it is unknown how the precursor is exactly processed. Nevertheless, the presence of putative convertase cleavage sites, highlighted in red, suggests the presence of A-, B- and C-domains quite similar to those in insulin. However, unlike insulin or IGF, the putative B-chain of dilp7 has a long N-terminal extension that I propose to call the F-domain. The latter is well conserved in dilp7 orthologs from other bilaterians (Fig. 4). 


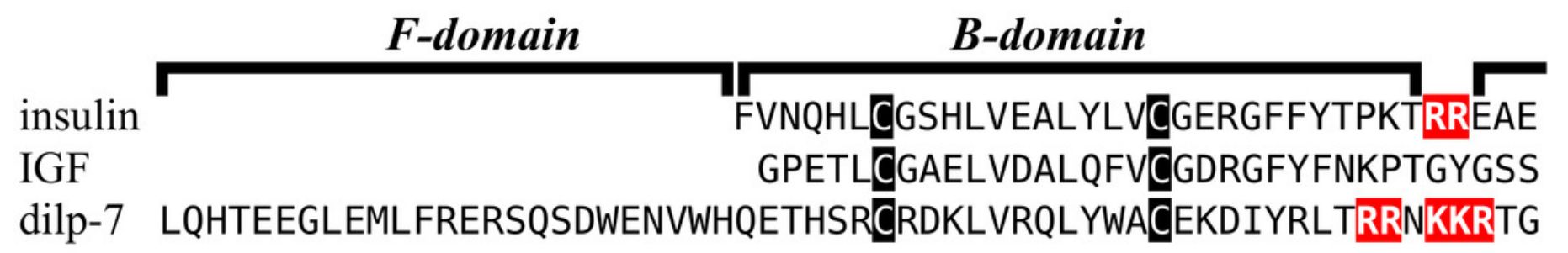

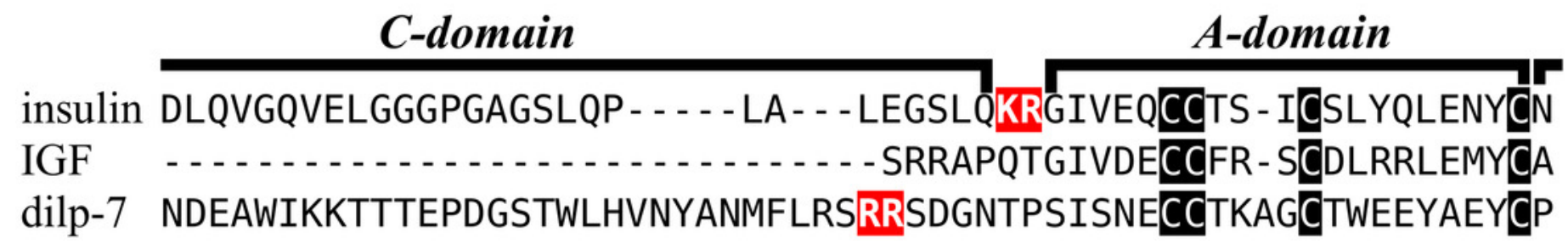

insulin

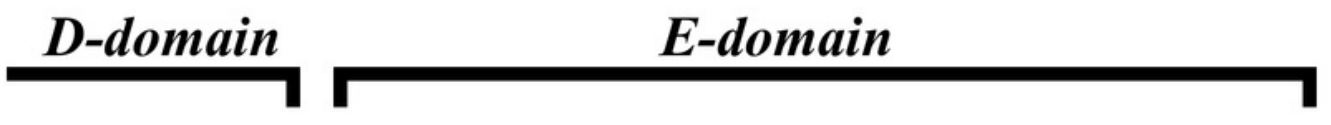

IGF PLKPAKSARSVRAQRHTDMPKTQKYQPPSTNKNTKSQRRKGSTFEERK

dilp-7 SNKRRNHY 


\section{Figure 2}

Sequences of selected ambulacrarian IGF.

Partial IGF sequences from selected ambulacrarians are illustrated to show their sequence similarity. The A-, B- and C-domains of the insulin core are aligned, but not the putative Dand $\mathrm{E}$ - domains, as their amino acid sequence is only conserved in closely related species (Fig. S1). Not aligning D- and E- domains allows the visualization the context of putative convertase cleavage sites. None of the arginine or lysine residues conform to a typical arthropod or vertebrate convertase cleavage site. Although the sequence of the latter part of the IGF precursors is not well conserved, all of them are rich in positively charged amino acid residues. Conserved cysteine residues are indicated in red, conserved amino acid residues are highlighted in black and conserved substitutions in grey. The arginine and lysine residues in the D- and E- domains are highlighted in blue. 
Anneissia

Strongylocentrotus -1

Strongylocentrotus -2

Apostichopus-1

Apostichopus-2

Acanthaster-1

Acanthaster -2

Ophiothrix-1

Ophiothrix-2

Saccoglossus

Ptychodera

Schizocardium

\section{Anneissia}

Strongylocentrotus -1

Strongylocentrotus-2

Apostichopus-1

Apostichopus-2

Acanthaster-1

Acanthaster -2

Ophiothrix-1

Ophiothrix-2

Saccoglossus

Ptychodera

Schizocardium

\section{Anneissia}

Strongylocentrotus-1 Strongylocentrotus -2 Apostichopus-1

Apostichopus-2

Acanthaster-1

Acanthaster-2

Ophiothrix-1

Ophiothrix-2

Saccoglossus

Ptychodera

Schizocardium

\section{Anneissia}

Strongylocentrotus -1 Strongylocentrotus -2 Apostichopus-1

Apostichopus-2

Acanthaster-1

Acanthaster-2

Ophiothrix-1

Ophiothrix-2

Saccoglossus

Ptychodera

Schizocardium

Anneissia

Strongylocentrotus-1 Strongylocentrotus -2 Apostichopus-1 Apostichopus-2 Acanthaster -1 Acanthaster -2 Ophiothrix-1 Ophiothrix-2 Saccoglossus Ptychodera Schizocardium
QP NHVRRY CGS ELT S ELERRCALKGGFN SP KKQE S P-- - - - - - - - - - - - - - - - -- SFP LL CGQELVKAVAAV $----S F R L C G R E L A D A L A V V$ $---S G Q R Y C G E A L L E A M A Y V$ $----A Q R Y C G T N L A D A L R I V$ $---A V I Q V$ CGNDILDALKSV $----W Q R I C G E Q I V E T V S I V$ $----W Q R L$ $----S Y L$ - - - WDKLCGRTLVDVLALI --- WDRL CGR SLADMLALV ---- WDKL CGR TLADMLS LV
$---------Y$ YWNQE KR I EATS--- - - - - - TERAKE INIVYE - - KRSAGIFELETRAKTFLKSGI SRGETRRSKRGARTGLIVTE - - -AQKD SP I VP H HVAS SF L GS S S -ASAH SRQRRRVRT GQI VNE -----VSRSPFLTEERAN SF LTNE-------RTRKTRRTGRIVTE --------PEVI P RQRAS SFITTDS---ENHHPRRLRRGTGIVTE

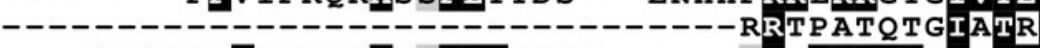
--- KREAE LFQDERTAK SFLGTH I G------SRQRRRTGRIATE SDTNNAES NP F RGES EAK SF L GL--------SRQKRRT GRI VHE IVYSFLTDPPLLTERQAKTFT-KSG----------RTRTGKIVTE $---K V K R E S P F R S G M E A N D F F$ GN I S-SKEKRRQRRRS GS GKI VDE -KSRRARE TVEATQEEANGFF GVG---S--GRTKRRRGS GI IVVE --- LPRE T IFQTQEDAH KEFGASV-FG--ERTQRRRGS GLI VAEC

HSACTEAFIDS LNRCSVSHLES DKECSNNIMES DNPCSQRNLES EKACDREVLET ISYCETSVLEK EKVCSYDIVES NN I CNYRI IES DNHCDMQI IES HQACDYTTLES DKICDYSTIES EKSCDYATIES

FCLSSNKDEDTTVESDTVETTTITGKKRKPTRKPKNP LKRSRKPKGSSE INSEQSASN CNPLPPDAVHDAEVH IRLEKSAEEDADEGRPQDGPSQLDTATGTVPETEMSETRGRV Y NRRTPEVPPESAISENPSEEITEDSTLRTDGESTEIRTDTNPATNLEVPSPDANTP Y CNVATTQTTEIPTELTTEGTTTEPAASPRRNSRN IEADGTAAAAGGGSGQGNGRGKG CNPHVTP TLALASLVTSLMTRSPTPPSSEPSSSSSSSS SRNEDRFPMTDNALGEDY Y CNPPSTSQSQTAAAP PRITTTPDERRANE IVVDETGQT GNTNSQMLRGGNAMGAGSR $Y$ CNP WPVVEDRDD P MLAP VAP GRVRQDKSADADL L LRPD IAE I SE DKS S LLRQAAEKूD Y CNP WPTT T T TATT TQSPEP L P NEQEGGYLTDE I QMKH I TRGQEDNSVDLLSEGSDLR $Y$ CAP LQEG $Q V$ KF T SRNLDFVNEANNVVEEP SVRVP QQVE ENKIVE E TVP YVS $Q A$ IVGE $Y C A P L P E G V V A D D S I K R F L S Q S F G N D F$ KDTANEDKLEIVTVVRP S HDEMDGTETRIED Y CAP WPKD IDP AKKIEGFKEGTWEEEDYHRKY HPESVEQPNANPEEPTPEPTTTDLDK YCAPWPKDMDP ALRF AGFKYGSWEDEDYYRKYHPEEFTQPDLTTWIASTDSANHDEHF

TELP SQTE P TKDKNGRGDKNKKDKCNKKSRDKNNKP CRRKSRKD SRRKNRKKNKKNKP RIDAVERVLSERI I T TTTGSSP SP SRKKPRKDKSERRNSSREAKQARREERRRNRER DATATSDVEQPRSDNTTAVEKPRKKDNGKGKNSSLESSTKKNRT SKGMSKEDRRRIAS KGRH GRGNRREQDQTVDVTSAETEGNTEP PRP NQQENNEDNRGTP DQSEERPRDRCRG EGPTNEGP LTSGEPTPTENRI SNGPRGP S NAS SLELPTRTSTATTNSSRIVTEGAHL ANGTRAPPTEVVDGRSDDDDDAAGE INTSERVGSLTEPDEETGRDVATNRP HKTHSTE EPIDDLDTLENEYAD GGNVMLQAREGVKEEGAELGKEMEEGGEKMPFPEVVPTKKRRR DE TP MP T GRA T G GRS PQL GHD SADVDS GF HRF GD I GAEVEE SDS T I DNPSSDR---TTSDGF DWDSDVSETHN I LNG G GDMY INDQP RDDP SENDEEH I PKEKSI I KQINVTES NEHVTP P TRDVITETSSI I LDD INVNKQ I ISSNT SVEVKS KAGNTKP KREKKDRDNS SLESESRDNVD IEESRS KDESAESEESVTENDDLKSEETNDNQDEY SREEYIGRDKGP TTATPSEETTSSENGEHIKTVNKEDDTQVTGTHELEKDHKFAEYWMNEDKMSRKHKKA

TRRP KRWD SETTTLSDF LF SORF LQRAYDSDI DVDEITTEFGVVPEEDISSSISEEEL S SGGRSRNGRRKDKDNDRA SRAKRHGLNLWRNMF SDKF F SD I P GL ENQP NL H PVNGRA DERRASRERKKEL SRERRKRLKLQQRKDKKKKKRL E SAERNRGTD HMGL SED STLIAR SKKKGKCRNQDRVEEEPTQDRIEEEPTTSREVSSTDGLSRERGSGSGGGRNRGNGKGK AESSDQS LEDTDSESEAP TKGASHERTRKKQKKQRTRP PKKPKKL SRERKERKKKKE RSKNRT SKS ERRRRRT NRRRS S SERRML SSERKREDATRKLRRKEQRISRKQP HSNKR VEGRRSRENSRDRNGKSEGKSKRKSGSREGGRSFRRRGKN SRRKKGRD GRERSKRWEA QTDEILDEDTDSENSESRLS I GATRGNS GRTRP THRPTSRH SRRKNSRERKRNRTRTR S SKKRS HP KPKRSRKKQRLQRIRKKARG TRKTKLRHVKVKSRSTP I QQ I ETTTTMKPF FRKHKKAP TKKLFKEKKL SEDNKKKKSRAKSRNSTKVKP TYVSSMTTSDEETITRPQG KRLMKERRARKSRTKKGNNTKSKS I LGKLVENMETESPTNWQRDG TDERWWTVEDP HF 


\section{Figure 3}

Sequences of selected echinoderm GSS.

Sequences of selected echinoderm GSS. Sequence alignment of a few echinoderm GSS showing relatively conserved A- and B- domains of the insulin core sequence and likely KR convertase cleavage sites that can be expected to be cleaved by neuroendocrine convertase as well as a few potential furin sites. Conserved cysteine residues are indicated in red, conserved amino acid residues are highlighted in black and conserved substitutions in grey. The arginine and lysine residues that form likely - or possibly in the case of Apostichopus GSS-2 - part of a convertase site are highlighted in blue. For the alignment of a larger number or echinoderm GSS sequences see Fig. S3.

\author{
Strongylocentrotus \\ Apostichopus-1 \\ Apostichopus-2 \\ Acanthaster -1 \\ Acanthaster -2 \\ Ophiothrix-1 \\ Ophiothrix-2 \\ strongylocentrotus \\ Apostichopus-1 \\ Apostichopus-2 \\ Acanthaster -1 \\ Acanthaster -2 \\ Ophiothrix-1 \\ ophiothrix-2 \\ Strongylocentrotus \\ Apostichopus-1 \\ Apostichopus - 2 \\ Acanthaster -1 \\ Acanthaster -2 \\ Ophiothrix-1 \\ Ophiothrix-2
}
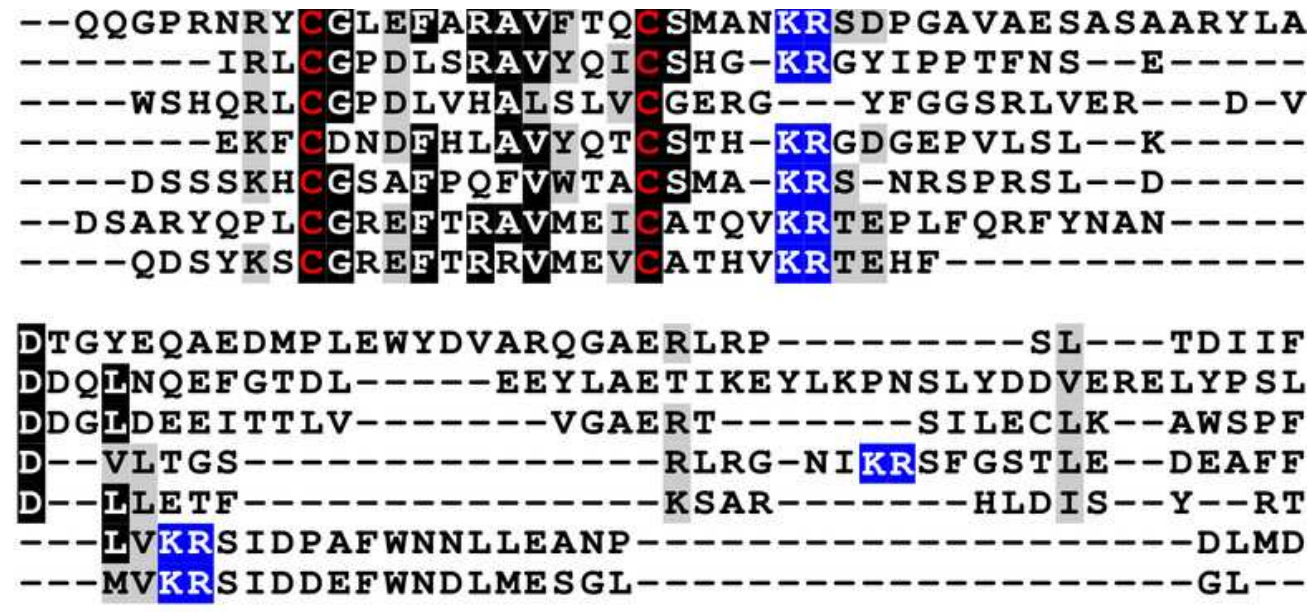


\section{Figure 4}

Sequences of selected dilp7 orthologs.

Sequences of selected dilp7 orthologs. Sequences of Drosophila dilp7 and several

ambulacrarian orthologs illustrating well conserved sequences, not only in typical insulin core of the peptides, but also in the F-domain (underlined in blue). Note that the sequence conservation of these peptides is stronger than in the IGFs or GSSs (Figs. 1,2). Conserved cysteine residues are indicated in red, conserved amino acid residues are highlighted in black and conserved substitutions in grey. Likely convertase cleavage sites have been highlighted in blue. Sequences are from Spreadsheet S1 and Veenstra 2020b, a comparison of a larger number of sequences is presented in Figs. S5 and S6.

Drosophila

Anneissia

Strongylocentrotus

Apostichopus

Acanthaster

Ophiothrix

Saccoglossus -1

Ptychodera

Schizocardium

Drosophila

Anneissia

Strongylocentrotus

Apostichopus

Acanthaster

Ophiothrix

Saccoglossus -1

Ptychodera

Schizocardium

Drosophila

Anneissia

Strongylocentrotus

Apostichopus

Acanthaster

Ophiothrix

saccoglossus -1

Ptychodera

Schizocardium

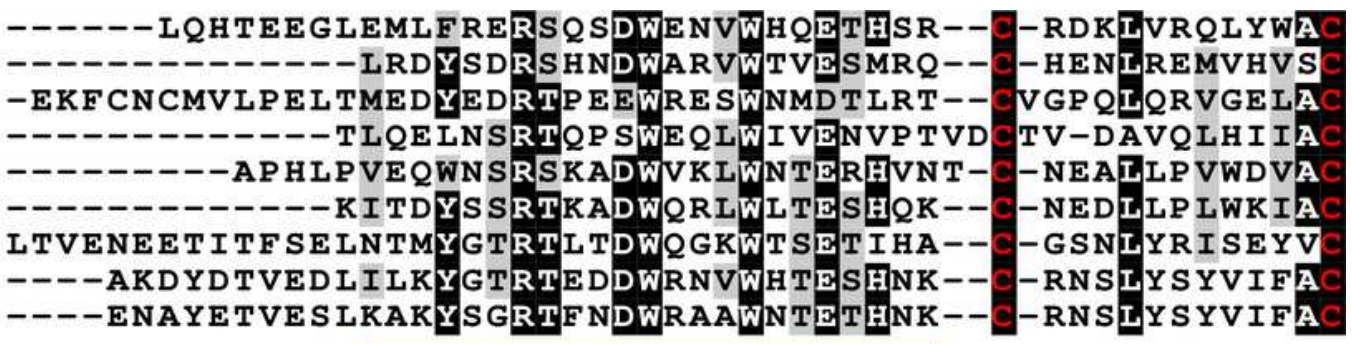

EKDIYRLTRRNKKRTGNDEAWIKKTTTEPDGSTWIHVNYANMFIRSRR--- RNDPRK-ISS KRS-------------------IFIPRNEAT GF LSRF L----I NDP RKT IVV KRSN-------------SDRDIF IP AKIAKAF L HYRHRKD-SNDVYKDHEG SRRRRF-------SDKRRRS--IFINF SEANNE LA-KTKRTHS QND IRK-I T-KRM---------------GREF LNEWTAKNF IAGS-- - - TYD IRK-IN-KRA---------------D PEVED SEAKAF I I GP------

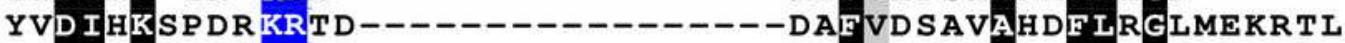
MVD I YATGDK KRAE--------------- P PEVEHS IAN SE LAGH RAEKRM MKD I HAS GDR KRGQ---------------- F PE LDHEVAD KE ISSSI-GKRM

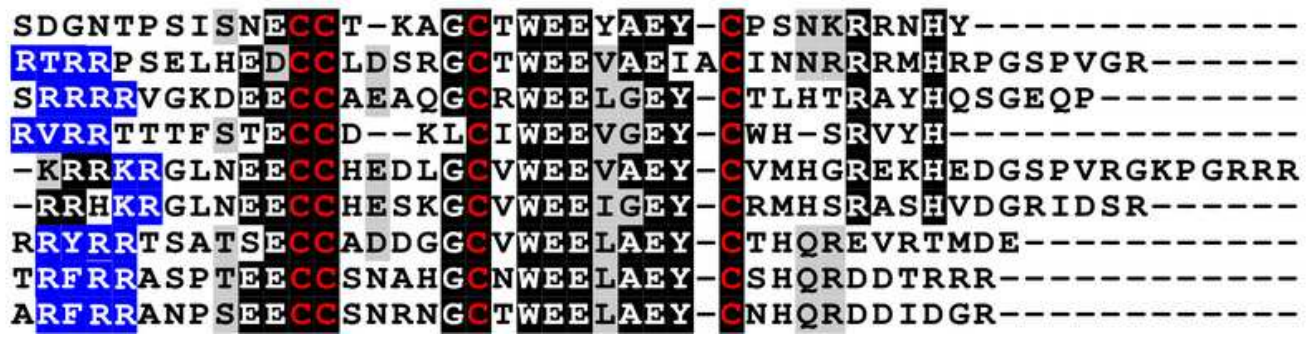




\section{Figure 5}

Sequences of selected ambulacrarian octinsulins.

Sequences of selected ambulacrarian octinsulins. Sequence alignment of a number of octinsulin sequences show that these sequences all have typical neuroendocrine convertase KR cleavage sites, suggesting these precursors are processed by enteroendocrine and/or neuroendocrine cells. Conserved cysteine residues are indicated in red, conserved amino acid residues are highlighted in black and conserved substitutions in grey. Likely convertase cleavage sites have been highlighted in blue. Sequences are from Spreadsheet S1, a comparison of a larger number of sequences is presented in Figs. S7 and S8. 
Anneissia

Strongylocentrotus Apostichopus

Acanthaster

Ophiothrix

saccoglossus-1

Ptychodera-1

Schizocardium-1

Saccoglossus-2

Ptychodera-2

Schizocardium-2

Saccoglossus -3

Ptychodera-3

Schizocardium-3

\section{Anneissia}

Strongylocentrotus Apostichopus Acanthaster

Ophiothrix

Saccoglossus -1

Ptychodera-1

Schizocardium-1

Saccoglossus-2

Ptychodera-2

Schizocardium-2

Saccoglossus-3

Ptychodera-3

Schizocardium-3

Anneissia

Strongylocentrotus Apostichopus

Acanthaster

Ophiothrix

Saccoglossus-1

Ptychodera-1

Schizocardium-1

Saccoglossus -2

Ptychodera-2

Schizocardium-2

Saccoglossus -3

Ptychodera-3

Schizocardium-3

Anneissia

Strongylocentrotus Apostichopus

Acanthaster

Ophiothrix

saccoglossus-1

Ptychodera-1

Schizocardium-1

Saccoglossus-2

Ptychodera-2

Schizocardium-2

Saccoglossus -3

Ptychodera-3

Schizocardium-3

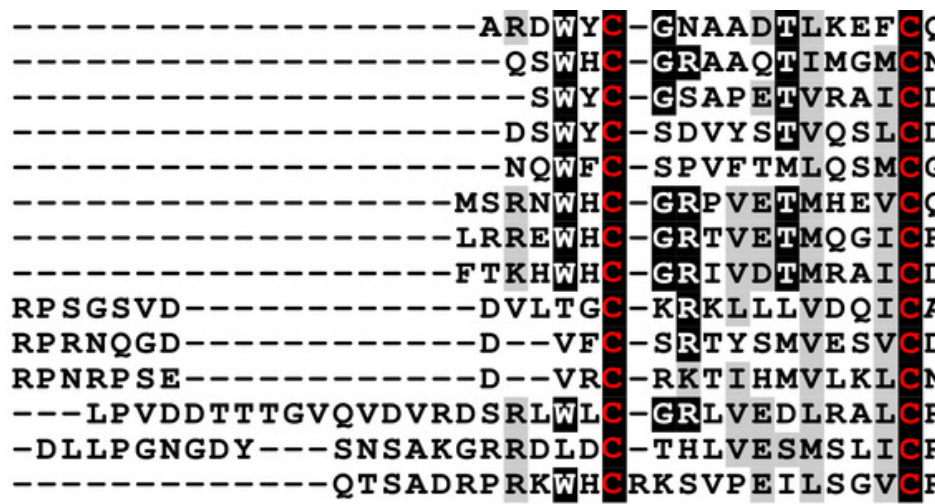

QS CYASTRAHN--ALSLP NSCYASHDKRS------YAGGIHTR--AFKRS DSCYAGF DKRT-----GSCYAGVDKRS-----QGCYAGHVRPR-----RGCYAQP SERS-----DGCYASP TARD-----AGCYAP P DIINNVNFDLT DGCYATTQDS SPKSESAM NGCLAP IESEVENN--TI RGCYAG---P------RGCYATDQGV -----------QTSADRPRKẄHCRKSVPEILSGV

SIKA-----KKDGMFLTKEGASGYLEAKRTRL--------FSS-LHLNHRQHETT I SKP SY-- - TP AKPFLHKRNAVHFLRT TKREIESRP SMGDTAIEVAVERRS TGNR SSD I IS---IYKD PFLKKSNALNELLPRSHTP-------S-----SIIKRGIRRS NSITRP---I -EEPFVERKNAVDFFKRGTAR--------G------------TRR DNSDTLSQKQSLDAFIQREVAYSFIKRTSVG--------DT----F LRNARNTHH NTRS----VDGVQAFI SRRDANMFTKGMSPD-------------V----KRAIDG T--N----EAERQAFI GKEEAS SFTKSVP---------------------TIVRR V--G----SVKGLPELKKHEASTETRTRS---------------------SVQKR

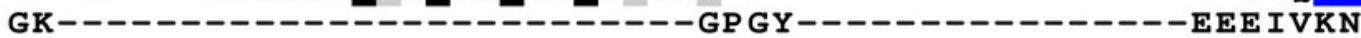

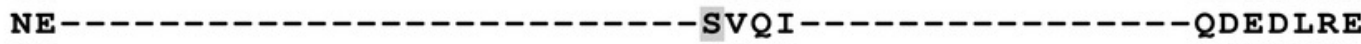

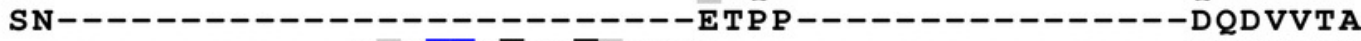
--------------DI SKREASKFMQFNA-------------------HTIRQSR $--------------T V N K R L A S S F I P T T T T P-------------R-----N K I Q R$

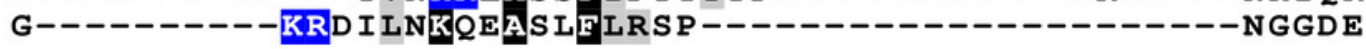

NFVTECCYNPCSSFEMIKYCCPTRQIVLHNRNPNSSEDK--------------GFIHECCNKF CDPGEMVIY GFI GECCEKN CEI REMVFY GIVDECCHRQ CAVSEMMLY GLIDECCTQQ CDTGEMILY GLI EECCY SQCSITHMITY GLLEDCCYRR CNLQKMMTY GIIEHCCNHHCSF TEILIY QIKEACCKEY CPI P KIIEF KIRDKCCNRR CT I HKMMQF KVREVCCDNYCSLDKIIEF GI IEDCCYH T CP T ERKI QY GI IDECCRNRCSVERKI QY EKRQI AEKQREYASFFPEIFRNRIRHT-- - - - - - - EQKQR YYTFVGWLKRR--------------QERQREWH I MMGL YNK----------------AEVQNEFQVFINILGNTDESSENDGDDGEESSSV AERQRELNNFFSLLNQKDNGST----------EERSEFFYSFIGLLRMDDEDTDASLEKGNGDVEA

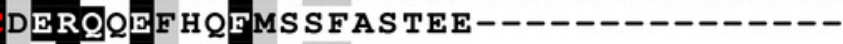
EARRNEF HKFLALMGNTDN------------EDLQQEFREMSFVSNSK--------------FEVQAQYRLFMESAI----------------DEIQKFFAFF SLFGS--------------LI INECCLRTCTV I EKI HY CCREKQI ELY I I IQS APWLVDNQR 


\section{Figure 6}

Sequence comparison of selected ambulacrarian multinsulins and dilp7 orthologs.

Sequence comparison of selected ambulacrarian multinsulins and dilp7 orthologs. Three different sets of sequences are compared. The top five sequences are dilp7 orthologs, the next five are multinsulins having three disulfide bridges and the last five multinsulins having four disulfide bridges. Note that although the multinsulins and the dilp7 orthologs share some sequences similarity this does not include the F-domain. Like the octinsulins these sequences all have typical neuroendocrine convertase KR cleavage sites, suggesting they are processed by enteroendocrine and/or neuroendocrine cells. Conserved cysteine residues are indicated in red, conserved amino acid residues are highlighted in black and conserved substitutions in grey. Likely convertase cleavage sites have been highlighted in blue. Sequences are from Spreadsheet S1, a comparison of a larger number of sequences is presented in Figs. S9 and S10. 


\section{Figure 7}

Position of introns in ambulacrarian irp genes

Schematic representation of the location of the cysteine residues, indicated as purple rectangles, and introns, represented by green T's, in the coding sequences of the various types of ambulacrarian insulin-like genes. Numbers indicate the phase of each intron. All genes share the typical phase 1 intron present in insulin-like genes, whereas dilp7 and multinsulin genes also share a phase 2 intron. Signal peptides indicated as interrupted bars.

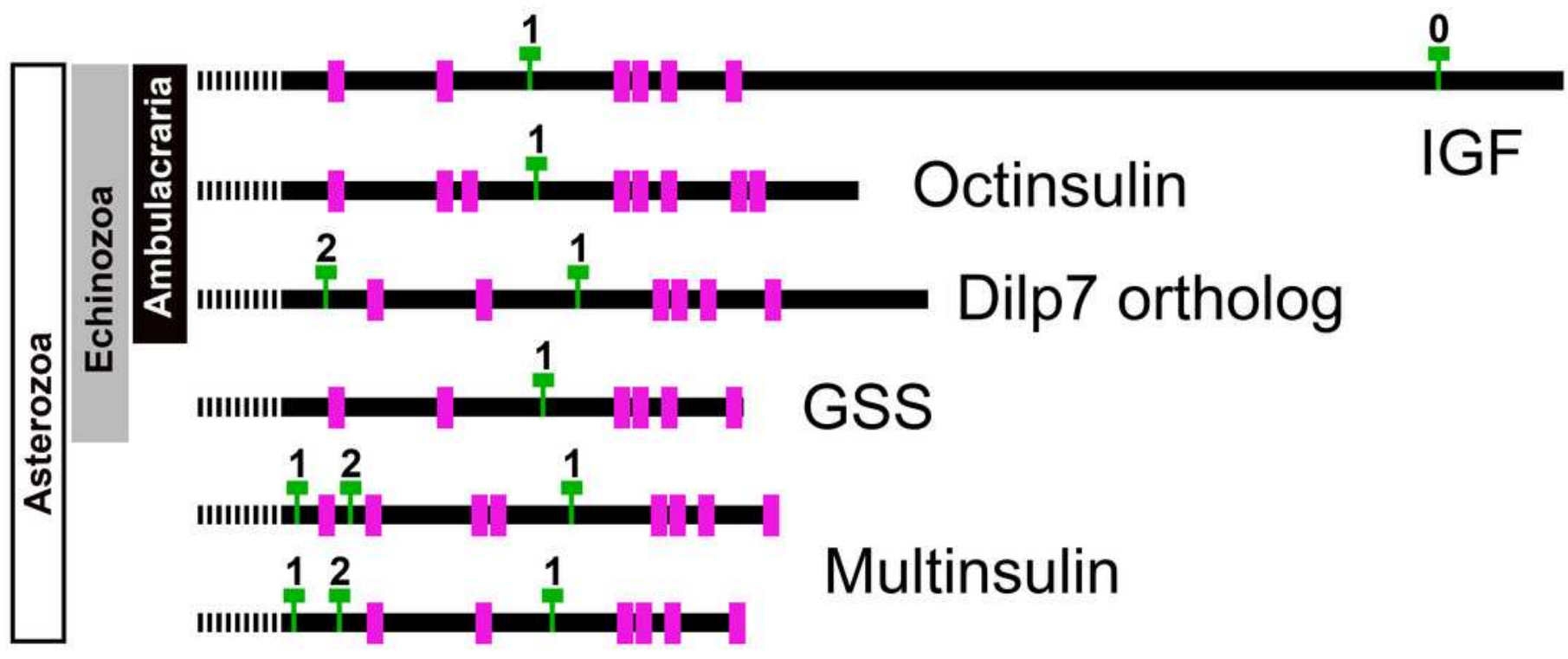




\section{Figure 8}

Synteny of ambulacrarian irp genes.

Schematic representation of the relative localization of different irp genes in several arthropod and ambulacrarian genomes. Arrow heads indicate transcription direction of the various genes, the numbers below the line indicate the number of nucleotides between the coding regions of adjacent genes in kilo base pairs. Note that the relative organization of the two insects - the cockroach Blattella germanica and the stick insect Timema crisitinae - is the same as in the hemichordate Saccoglossus kovalewskii and remarkably similar to that of the sea urchin Strongylocentrotus purpuratus and the sea cucumber Holothuria scabra. In the spider Pardosa pseudoannulata and the sea cucumber Apostichopus japonicus some of the genes are also next to one another. However, in the sea stars Acanthaster planci and Pisaster ochraceus synteny has been lost. Arthropod data from Veenstra, 2020b. 


\section{Pardosa}

Blattella

Timema

Saccoglossus
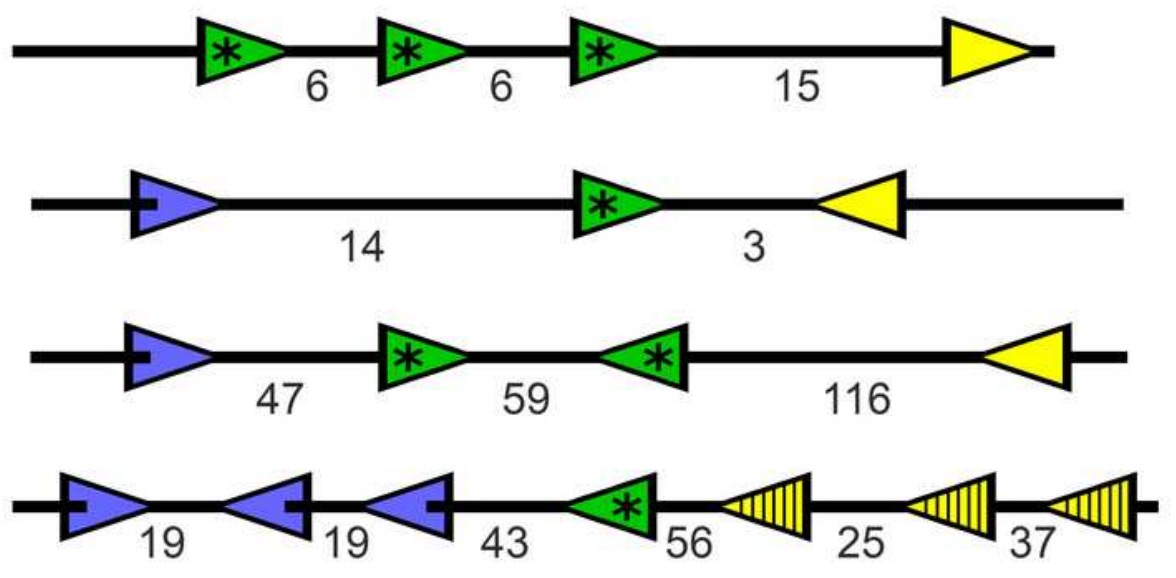

\section{Strongylocentrotus}

Holothuria

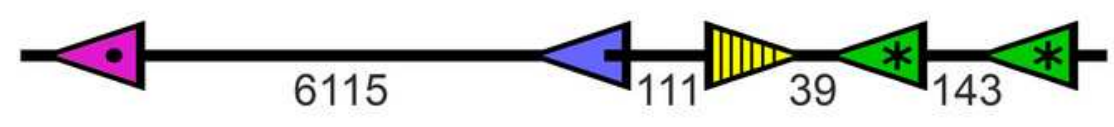

Apostichopus

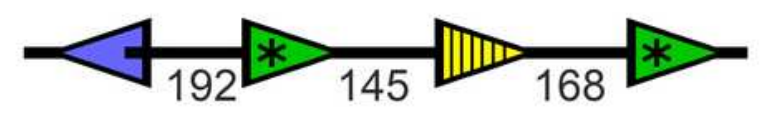

Pisaster
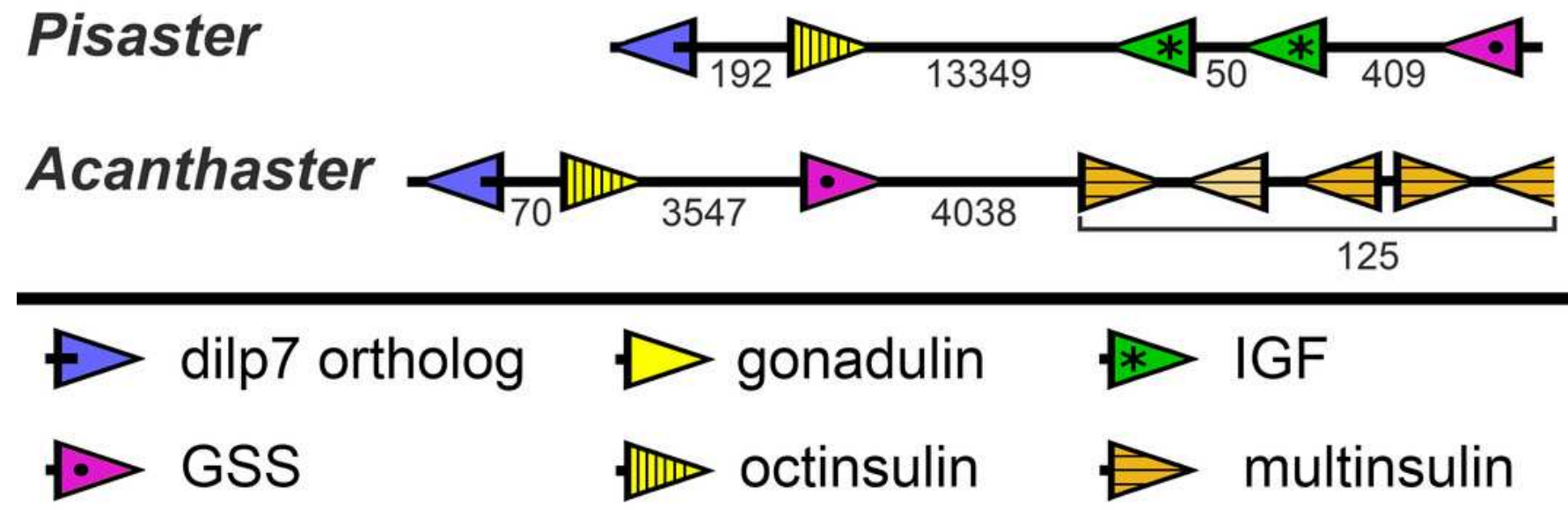


\section{Figure 9}

Radial sequence similarity tree of ambulacrarian irps.

The five different types of irps are clearly separated from one another. Note that the GSSs are similar to IGFs and seem to be related to them, while the multinsulins are most similar to the dilp7 orthologs. Echinoderm branches are in black, hemichordate branches in red. More extensive sequence comparisons and sequence trees are the supplementary data (Figs. S1S10). All sequences are from Spreadsheet S1. 


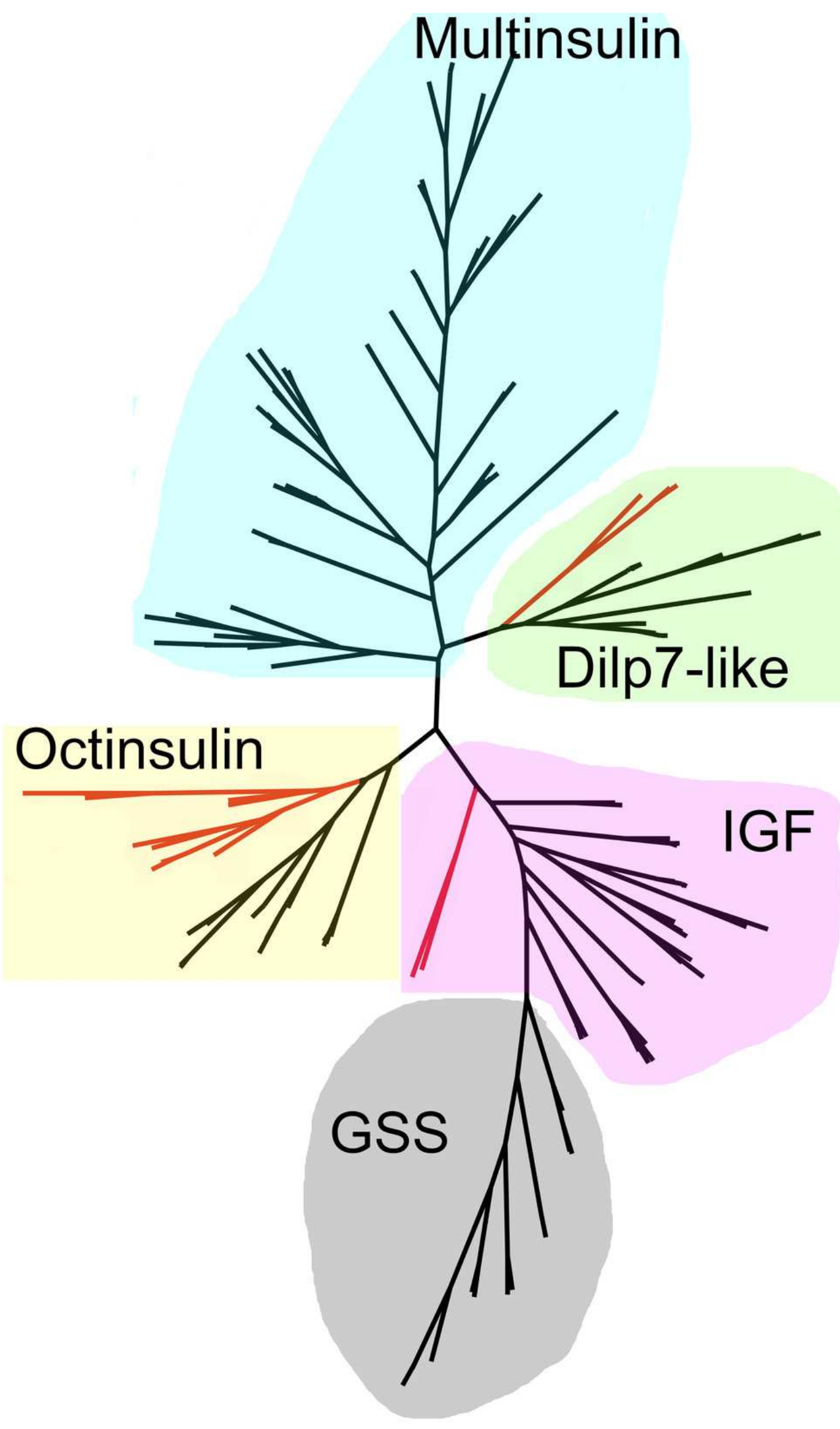




\section{Figure 10}

Phylogenetic tree of LGRs.

Phylogenetic tree constructed from the transmembrane regions of ambulacrarian LGRs that are putative receptors for irps. A few human and insect sequences have been added for comparison. The insert at the top shows the same data to which the glycoprotein LGRs have been added and where characteristic ligands for each branch have been identified. Numbers in blue indicate the apparent probabilities as determined by Fasttree. For details of the glycoprotein LGRs see Fig. S11. 


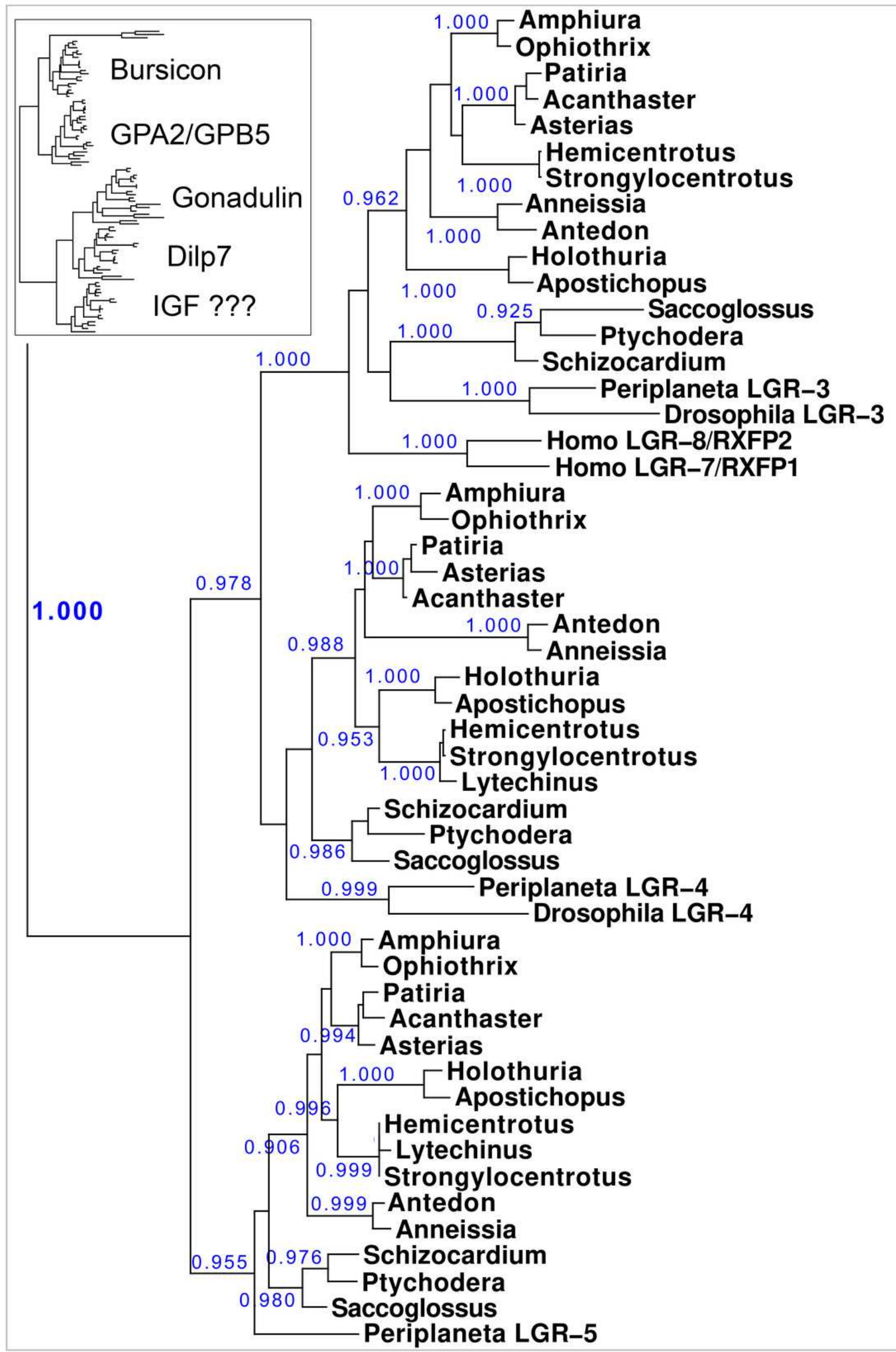




\section{Figure 11}

Ectodomains of ambulacrarian LGRs.

Ectodomains of ambulacrarian LGRs. Schematic representation of the various domains of the putative receptors for ambulacrarian insulin-related peptides. Each green circle symbolizes an LDLa repeat and each purple rectangle an LRR repeat, while the yellow oval indicates the seven transmembrane regions. The top representation corresponds to the gonadulin and dilp7 receptors (Figs. S11,S12). Note though, that the latter are somewhat variable, notably in the sea stars of two species of the Patiria genus and Acanthaster planci those receptors have two LDLa repeats (for details see Fig. S12). The bottom representation corresponds to the GRL101 receptors (Fig. S13).
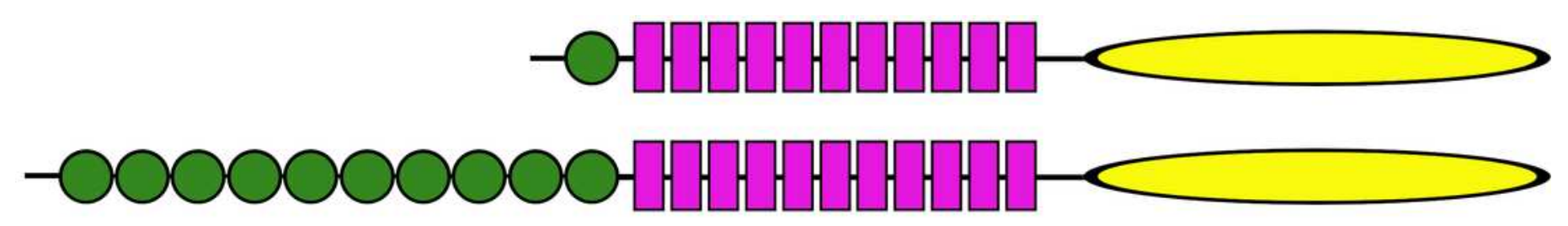


\section{Figure 12}

How echinoderm irps may have evolved.

A represent an early metazoan in which an arch irp is a ligand for both an LGR and an RTK. B represents an early protostome or deuterostome that has three irps, an IGF and a dilp7 ortholog as well as gonadulin/octinsulin ortholog that evolved from local gene duplication from the arch irp. All three of these ligands each each their own LGR and at least two of them, IGF and the dilp7 ortholog, can also activate the RTK. C represents the Asterozoa where the dilp7 gene got duplicated and yielded several multinsulin genes which are represented here as one. The Asterozoa also have one or two GSS's that evolved earlier during echinoderm evolution. Both multinsulins and GSS's act exclusively through the RTK. Closed arrows indicate gene duplication events and interrupted arrows show ligand-receptor interactions. The question mark conveys uncertaintity with regard to whether or not the gonadulin/octinsulin peptides are able to activate the RTK. 

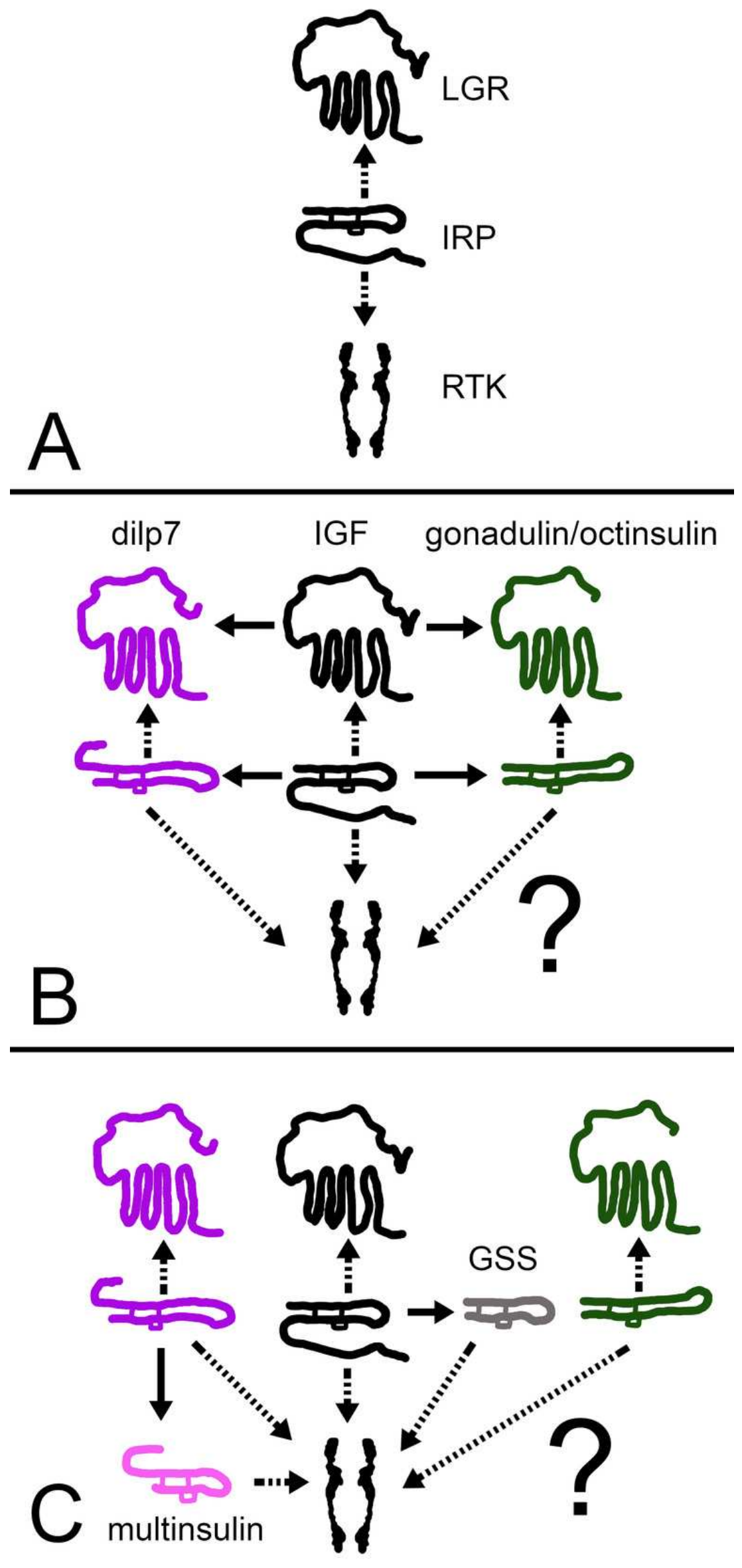